\title{
Nanoparticles in Combating Neuronal Dysregulated Signaling Pathways: Recent Approaches to the Nanoformulations of Phytochemicals and Synthetic Drugs Against Neurodegenerative Diseases
}

\author{
Sajad Fakhri (iD) \\ Sadaf Abdian (iD) ${ }^{2, *}$ \\ Seyede Nazanin Zarneshan ${ }^{2, *}$ \\ Seyed Zachariah Moradi iD 1,3 \\ Mohammad Hosein Farzaei (D) \\ Mohammad Abdollahi (D) ${ }^{4,5}$ \\ 'Pharmaceutical Sciences Research \\ Center, Health Institute, Kermanshah \\ University of Medical Sciences, \\ Kermanshah, Iran; ${ }^{2}$ Student Research \\ Committee, Kermanshah University of \\ Medical Sciences, Kermanshah, Iran; \\ ${ }^{3}$ Medical Biology Research Center, \\ Kermanshah University of Medical \\ Sciences, Kermanshah, Iran; ${ }^{4}$ Toxicology \\ and Diseases Group, Pharmaceutical \\ Sciences Research Center (PSRC), The \\ Institute of Pharmaceutical Sciences \\ (TIPS), Tehran University of Medical \\ Sciences, Tehran, Iran; ${ }^{5}$ Department of \\ Toxicology and Pharmacology, School of \\ Pharmacy, Tehran University of Medical \\ Sciences, Tehran, Iran \\ *These authors contributed equally to \\ this work
}

\begin{abstract}
As the worldwide average life expectancy has grown, the prevalence of agerelated neurodegenerative diseases (NDDs) has risen dramatically. A progressive loss of neuronal function characterizes NDDs, usually followed by neuronal death. Inflammation, apoptosis, oxidative stress, and protein misfolding are critical dysregulated signaling pathways that mainly orchestrate neuronal damage from a mechanistic point. Furthermore, in afflicted families with genetic anomalies, mutations and multiplications of $\alpha$-synuclein and amyloid-related genes produce some kinds of NDDs. Overproduction of such proteins, and their excessive aggregation, have been proven in various models of neuronal malfunction and death. In this line, providing multi-target therapies carried by novel delivery systems would pave the road to control NDDs through simultaneous modulation of such dysregulated pathways. Phytochemicals are multi-target therapeutic agents, which employ several mechanisms towards neuroprotection. Besides, the blood-brain barrier (BBB) is a critical issue in managing NDDs since it inhibits the accessibility of drugs to the brain in sufficient concentration. Besides, discovering novel delivery systems is vital to improving the efficacy, bioavailability, and pharmacokinetic of therapeutic agents. Such novel formulations are also employed to improve the drug's biodistribution, allow for the co-delivery of several medicines, and offer targeted intracellular delivery against NDDs. The present review proposes nanoformulations of phytochemicals and synthetic agents to combat NDDs by modulating neuroinflammation, neuroapoptosis, neuronal oxidative stress pathways and protein misfolding.
\end{abstract}

Keywords: neuroprotection, apoptosis, inflammation, oxidative stress, novel delivery system, therapeutic target, pharmacology

\section{Introduction}

In recent decades, nanoparticles have shown significant implications in improving biodegradability/biocompatibility, therapeutic effectiveness, and drug pharmacokinetics while decreasing the adverse effects of current medications. ${ }^{1-3}$ The bloodbrain barrier (BBB) is a critical issue in managing neurodegenerative diseases (NDDs) since it inhibits the accessibility of drugs to the brain in sufficient therapeutic concentrations. The functional intricacy of the BBB is mainly ascribed to the brain capillary endothelial cells, which limit trans-cellular transit, as well as the tight and adherens junctions between the cells, which result in the limitation of
Correspondence: Mohammad Hosein Farzaei; Mohammad Abdollahi Email mh.farzaei@gmail.com; Mohammad@TUMS.Ac.Ir 
para-cellular flow. Thus, to overcome the pharmacokinetic limitations of drugs used against NDDs, employing novel delivery systems would be helpful. ${ }^{4}$

By passing BBB, nanoparticles have shown the potential of regulating several dysregulated pathways in NDDs, including oxidative stress, ${ }^{1,2}$ inflammation, ${ }^{5}$ apoptosis, ${ }^{6,7}$ and protein aggregation. ${ }^{8}$ Oxidative stress is commonly defined as a discrepancy between the activity of antioxidants and the generation of oxidants, which shows negative health benefits to play a fundamental part in the aggravation of several diseases. ${ }^{1,2,6,9-11}$ Modulating oxidative stress is one of the most effective support mechanisms of nanoparticles against NDDs. ${ }^{1,2}$ Furthermore, neuroinflammation is defined as a critical activator of the brain's innate immune system in a complicated pattern to an inflammatory state related to numerous molecular and cellular changes inside the brain. These changes inhibit glial cell activation while increasing the levels, concentrations, and releases of several inflammatory mediators, including chemokines, cytokines, and the formation of reactive oxygen species (ROS)/reactive nitrogen species (RNS). ${ }^{12,13}$ Nanoformulations have also shown the potential to modulate main apoptotic pathways, termed extrinsic (death receptor) and intrinsic (mitochondrial-dependent) pathways. ${ }^{14,15}$ Besides, nanoparticles play essential roles in decreasing the burdens of amyloid-beta $(A \beta) . A \beta$ is formed by the enzymatic degradation of an amyloid precursor protein (APP) cleaved in a series of stages, resulting in the creation and production of amyloid proteins. An imbalance in the design and subsequent elimination of $\mathrm{A} \beta$ results in the neuronal buildup that could be a precursor to some NDDs. ${ }^{8,16}$

Consequently, since phytochemicals are potential multi-target agents in targeting neuroinflammatory, neuroapoptotic, neuronal oxidative stress and proteins aggregation pathways, they would be potential alternative therapies in combating NDDs. In this line, targeting the aforementioned pathways by nanoformulations of phytochemicals and synthetic drugs ${ }^{1,8,17,18}$ could open new roads in combating Alzheimer's disease (AD), ${ }^{19}$ Parkinson's disease (PD), ${ }^{20,21}$ amyotrophic lateral disease (ALS), ${ }^{22,23}$ stroke, ${ }^{24-26}$ multiple sclerosis (MS), ${ }^{27}$ and Huntington's disease (HD). ${ }^{28}$

Previous reports have shown the potential of nanoformulations against some NDDs, with no focuses on phytochemical effects. $^{20,29-31} \mathrm{~A}$ recent study highlighted the nanoformulations of limited phytochemicals and some plant extracts against NDDs with no focus on dysregulated pathways. ${ }^{1}$ The current study aims to develop nanoparticles' therapeutic potential in combating neuroinflammation, neuroapoptosis, neuronal oxidative stress and protein aggregation with a promising approach to the nanoformulations of phytochemicals and synthetic drugs against NDDs.

\section{How Nanoformulations Modulate Neuronal Oxidative Stress, Inflammation, Apoptosis, and Proteins Aggregation in NDDs}

The term nanoparticles predominantly refer to small structures with size ranges from 1 to $100 \mathrm{~nm}$ that could be categorized according to their shapes, properties, or sizes. Carbon-based (carbon nanotubes and fullerenes), ceramic, metal, semiconductor, lipid-based, polymeric nanoparticles, ${ }^{1,2}$ peptide engineering techniques, ${ }^{32}$ DNA nanocage, and nanoenzymes are reported as the primary essential classes of nanoparticles. ${ }^{33}$ These compounds' nanoscale size and high surface area have given nanoparticles variant physical and chemical properties. Nanotechnology provides preferable drug delivery systems for enhancing the management of neuronal-related disorders via the diagnosis, monitoring, controlling, and repairing at a molecular level. Treatment with nanoparticles has shown considerable consequences like suitable biodegradability and biocompatibility, improvement of the therapeutic efficacy and drug pharmacokinetics, and decreasing adverse effects of the drug. Regarding exerting such effects, nanoparticles modulate major dysregulated pathways of NDDs, including oxidative stress, inflammation, apoptosis, and proteins aggregation. Such anti-inflammatory properties are dependent on several factors, including nanoparticles' high surface area to volume ratio, which facilitate the suppressive potential of associated drugs on enzymes, cytokines, and other components involved in the inflammatory process. ${ }^{5}$

\section{Neuronal Oxidative Stress in NDDs: Role of Nanoparticles}

Oxidative stress is usually described as a disparity between antioxidants' activity and oxidants production leading to undesirable health consequences in humans and showing an undeniable role in the intensification of variant disorders. ${ }^{34}$ This process triggers the onset or exacerbation of diseases by inducing DNA, carbohydrates, proteins, and lipids. Cancer, cardiovascular disease, chronic obstructive 
pulmonary disease, and asthma are related to oxidative stress and ROS production. Similarly, there is reliable evidence that oxidative stress may contribute to various NDDs like AD, PD, stroke, HD, and ALS. Oxidative damage to macromolecules is the hallmark of NDDs and accelerates the progression of such disorders. Oxidative stress could lead to neuronal cell death and promote toxic signalings/cascades. Accordingly, several studies reveal the exogenous and endogenous sources of oxidative stress and possible effective mechanisms in controlling those pathways. ${ }^{9,35}$ In addition, protein misfolding plays a pivotal role in generating ROS-induced NDDs. Although reducing oxidative stress seems to be the essential characteristic of nanoparticles, nanoparticle-related effects are contradictory and confusing. The nanoparticlesinduced oxidative stress could be related to the presence of metals, mitochondrial respiration, cell interaction, and immune cell activation. ${ }^{36}$

The intrinsic antioxidant properties of nanoparticles are not significant, and most of the reported antioxidant effects have been associated with the loaded antioxidant compounds. Nanoparticles have increased the bioavailability, solubility, and BBB permeability of antioxidant compounds, enhancing the efficiency and performance of such compounds. ${ }^{2}$ However, some oxide nanoparticles exert intrinsic antioxidant activity via triggering antioxidant mediators and scavenging the ROS and RNS. Cerium oxide $(\mathrm{CeO})$ nanoparticles can appropriately mimic the effects of variant enzymes involved in reducing oxidative stress, such as superoxide dismutase (SOD), catalase (CAT), and phosphatase. The use of $\mathrm{CeO}$ nanoparticles seems to be increasing due to such an inherent effect. $\mathrm{CeO}$ nanoparticles are memorable and exciting with unique properties that have attracted much attention due to their specific features, including their yummy regenerative potential and ROS scavenging activity. ${ }^{37}$ In the study of Caputo et al, the antioxidant potential of $\mathrm{CeO}$ nanoparticles emphasized that the antioxidant activity of $\mathrm{CeO}$ nanoparticles was considerably more than a vitamin $\mathrm{E}$ analog and $\mathrm{N}$-acetyl-cysteine to diminishing the oxidative signal of 2'-7'-Dichlorofluorescein promoted by irradiated titanium dioxide (TiO2) nanoparticles. ${ }^{38}$ In another study, Ragg et al reported that manganese oxide nanoparticles provided an intrinsic SOD-like activity and remarkably increased the magnetic resonance imaging (MRI) contrast, making it suitable for the imaging and treating cancer cells. $^{39}$
Similarly, treating transgenic mice with $\mathrm{CeO}$ nanoparticles led to the suppression of progressive left ventricular dysfunction and diminished the myocardial oxidative stress. It also refused the serum levels of C-reactive protein, monocyte chemoattractant protein 1 (MCP-1), and total nitrated proteins and the levels and expression of tumor necrosis factor-alpha (TNF- $\alpha$ ), interleukin (IL)-6, IL-1 $\beta$, and other pro-inflammatory cytokines in the myocardium. ${ }^{40}$ However, these nanostructures do not have sufficient therapeutic potential to be used without therapeutic options. For this reason, functionalizing these nanoparticles by adding the enzymes, natural and synthetic compounds increases their therapeutic effects. In addition to the key enzymatic antioxidant such as glutathione (GSH) peroxidase, SOD, CAT, other non-enzymatic antioxidants, including GSH, vitamin E, vitamin $\mathrm{C}$, vitamin A, as well as several phytochemical compounds protect the neurons from oxidative stress and show practical advantages in vivo and in vitro. Therefore, applying the supplemental enzymatic to scavenging the free radical is a rational approach to defend against the neuronal degeneration-induced oxidative stress and associated treatment to delay or prevent the progression/development of NDDs.

Targeting and accurate delivery of antioxidant compounds and enzymes to different body parts, especially the central nervous system (CNS), is another support mechanism of nanoparticles versus oxidative stress. ${ }^{41,42}$ Gil et al investigated the in vitro antioxidant and beneficial effects of nanocrystalline cerium dioxide $(\mathrm{CeO} 2)$ in elevating CAT and SOD enzymes in conjugation with nanocrystalline $\mathrm{CeO} 2$. Results demonstrated that antioxidant enzymes combined with nanoceria had shown suitable stability as antioxidant activity synergistically increased. ${ }^{43}$ Furthermore, Reddy et al attempted to enhance the bioavailability of SOD by providing a nanoformulation, encapsulating $\mathrm{SOD}$ in poly(D, L-lactide-co-glycolide) nanoparticles. It led to increased bioavailability, neuroprotection against apoptosis, neurological recovery, and reducing the infarct volume, level of ROS, and diminished the ischemia-reperfusion injury in the rat's model of focal cerebral ischemia-reperfusion injury. ${ }^{44}$ In a similar study, a new nanoformulation's in vitro neuroprotective activity was investigated. Results demonstrated that the intracellular neuronal uptake of SOD increased when encapsulated in poly(lactic-co-glycolic acid) [PLGA] nanoparticles. Additionally, its neuroprotective activity in cultured human neurons was enhanced versus the oxidative stress phenomenon. ${ }^{45,46}$ 
Platinum $(\mathrm{Pt})$ is another helpful agent in nanomedical studies that can catalytically convert $\mathrm{O} 2$ to $\mathrm{H} 2 \mathrm{O} 2$ and then facilitate the conversion of $\mathrm{H} 2 \mathrm{O} 2$ to $\mathrm{O} 2$ and $\mathrm{H} 2 \mathrm{O}$. This essential and practical feature of $\mathrm{Pt}$ makes it an attractive and suitable candidate for modulating oxidative stress conditions through mimicking the CAT/SOD enzyme effects. $^{47,48}$ Moreover, improving the delivery of CAT via the generation of CAT-loaded nanoparticles provided better in vitro neuroprotective activity against the oxidative stress induced by $\mathrm{H} 2 \mathrm{O} 2$. CAT-loaded nanoparticles decreased $\mathrm{H}_{2} \mathrm{O}_{2}$-induced mitochondrial membrane distortion, DNA damage, cell membrane integrity, and protein oxidation. ${ }^{49}$ Also, Martín et al designed and investigated the in vitro antioxidant activity of new Pt and gold nanoparticles supported on Fenton-treated diamond nanoparticles (Pt/HO-DNP and Au/HO-DNP). The characterized structure could cross the cell membrane and exert significant biocompatibility and meaningful antioxidant activity versus ROS-induced cellular oxidative stress in a hepatoma cell line. ${ }^{50}$

In addition, several studies were performed to investigate the beneficial effects and the antioxidant potential of various types of functionalized nanoparticles. The variant nanoparticles, including silver, gold, iron, copper oxide, and zinc oxide, exerted significant antioxidant activity. Briefly, the considerable role of nanoparticles in the prevention and control of oxidative stress in NDDs is not hidden from anyone, and these systems can play a more vital role in various diagnostic and therapeutic stages of NDDs in the future.

\section{Neuroinflammation in NDDs: Role of Nanoparticles}

Neuroinflammation is the stimulation and enabling of the brain's innate immune system in a complex replication to an inflammatory condition associated with several molecular and cellular variations within the brain. This response leads to interfering with the activation of glial cells and enhancing the levels, concentration, and release of variant inflammatory mediators, like chemokines (CXCL1, CCL5, CCL2), cytokines (TNF- $\alpha$, IL-6, IL-1 $\beta$ ), as well as the production of ROS and RNS. ${ }^{13,51}$ Moreover, enhancing the edema, infiltration of peripheral immune cells, elevating the breakdown, and permeability of the BBB are also other harmful mechanisms that occur during neuroinflammation. ${ }^{13,52}$ Mast cells are other parts of the inflammatory and immunoregulatory process that exerts their roles via releasing variant inflammatory mediators, including cytokines, chemokines, histamines, and leukotrienes. Moreover, mast cells promote the allergic inflammatory responses by enhancing immunoglobulins $\mathrm{E}$ ( $\mathrm{IgE}$ ) synthesis by B-lymphocytes. ${ }^{5}$

Additionally, nuclear factor kappa-light-chain-enhancer of activated B cells (NF- $\mathrm{kB}$ ) signaling is another crucial pathway that can activate and affect more than 500 genes involved in the neuroinflammation process. The role of $\mathrm{NF}-\kappa \mathrm{B}$ is critical in regulating neuroinflammation-associated disease pathogenesis. ${ }^{53}$ Neuroinflammation plays a major role in fighting the pathogenesis progression of neurodegenerative and psychiatric disorders which leads to neuronal system damage. It seems that regulation of neuroinflammation can contribute to suitable attractive strategies to prevent, treat, and improve the condition of patients with psychiatric and NDDs, including $\mathrm{AD}, \mathrm{PD}$, stroke, ALS, HD, and MS.

Nanoparticles have shown significant anti-inflammatory potential in the past few decades. These anti-inflammatory effects are due to the large ratio of surface area to volume, which predisposes nanoparticles to exert more appropriate effects in inhibiting the enzymes, cytokines, and other factors involved in the inflammatory process. Previously, the in vitro and in vivo anti-inflammatory activity of the variant nanoparticles, including gold, copper, silver, selenium, zinc oxide, magnesium oxide, iron oxide, and $\mathrm{CeO}$, were reported. ${ }^{5}$

Zinc oxide nanoparticles demonstrated anti-inflammatory activity via blocking the pro-inflammatory cytokines such as TNF- $\alpha$ and IL- $1 \beta$ that lead to the downregulation of inflammatory responses, reducing the proliferation and differentiation of mast cells. Furthermore, zinc oxide nanoparticles diminished caspase- 1 in activated mast cells, suppressed the NF- $\mathrm{\kappa B}$ signaling and lipopolysaccharideinduced NF- $\mathrm{KB}$ as well as reduced the cytosolic degradation of I $\mathrm{I} B \alpha$, and production of malondialdehyde, IL-1 $\beta$, TNF- $\alpha .{ }^{5,54,55}$ Inhibiting the proliferation of mast cells, regulating the level of $\mathrm{p} 53$ protein, suppressing the expression of cyclooxygenase (COX-2) and inducible nitric oxide synthase (iNOS) are some of the other anti-inflammatories mechanisms of zinc oxide nanoparticles. ${ }^{5}$ Furthermore, gold nanoparticles decrease ROS production, diminish the lipopolysaccharide-induced production of several pro-inflammatory cytokines such as TNF- $\alpha$, IL17 , IL-12, and IL-1 $\beta .{ }^{5,56}$ Treatment with gold nanoparticles led to the modulation of phosphoinositide 3-kinases (PI3K), mitogen-activated protein kinase (MAPK) 
signaling pathways, and downregulation of pro-inflammatory cytokines in hepatic stellate and Kupffer cells. ${ }^{5,57}$ Gold nanoparticles also showed the potential of suppressing $\mathrm{A} \beta$ aggregation in $\mathrm{AD} .^{58}$

Similarly, silver nanoparticles also showed anti-inflammatory activity via diminishing the expression of hypoxiainducible factor 1-alpha (HIF-1 $\alpha$ ), reducing the generation and secretion of several pro-inflammatory cytokines such as TNF- $\alpha$, IL-13, IL-12, IL-9, IL-5, and IL-4. Moreover, treatment with silver nanoparticles diminished the expression of the COX-2 gene, reduced the mucin hypersecretion, decreased VEGF levels, decreased the levels of VEGF, and suppressed the T helper type- 2 cell-mediated inflammation. ${ }^{5,59-62}$ Selenium nanoparticles exert the antiinflammatory response via suppressing the phosphorylation of IкB- $\alpha$, inhibiting the release of NF- $\kappa \mathrm{B}$, and reducing the lipopolysaccharide-induced release of proinflammatory mediators. Furthermore, the expression of COX-2 and iNOS enzymes was inhibited after treatment with selenium nanoparticles. ${ }^{5,63}$ The fibrinogen into fibrin converter enzyme, thrombin, can augment the inflammatory response through amplifying the downstream signaling or mediators via activation of protease-activated receptors and enhancing the levels of cytokines and P-selectin. Previous studies demonstrated that $\mathrm{TiO} 2$ nanoparticles led to the suppression of the inflammation via increasing levels of the thrombin-antithrombin complex, thrombin inactivation, and suppressing the protease-activated receptor's pathway. ${ }^{5,64}$ Also, $\mathrm{CeO}$ nanoparticles decreased the inflammatory response, neuronal death, microglial activation, oxidative stress, reduced TNF- $\alpha$, and neurodegenerative events in the rat's model of retinal neurodegeneration. ${ }^{65}$

Besides, green synthesized nanoparticles showed more significant anti-inflammatory effects. The gold nanoparticles synthesized from some plants showed significant neuroprotective activity via enhancing motor coordination and diminishing the neuroinflammation in vitro and in vivo models of PD. ${ }^{66}$ In a similar study, Park et al investigated the anti-neuroinflammatory activity of the gold nanoparticles capped with plant extracts. Synthesized gold nanoparticles showed anti-neuroinflammatory effects via diminishing the levels and activity of pro-neuroinflammatory cytokines and mediators, decreasing the production of ROS, downregulation of p38MAPK, NF- $\mathrm{BB}$, extracellular signal-regulated kinase (ERK-1/2), Janus kinase (JAK)-signal transducer and activator of transcription (STAT), c-Jun N-terminal kinases (JNK), IKK- $\alpha / \beta$, signaling pathways as well as enhanced the activation of AMP-activated protein kinase (AMPK) and nuclear factor-erythroid factor 2-related factor 2 (Nrf2), and upregulation of NQO1 and heme oxygenase-1 (HO-1) expression. ${ }^{67}$ Moreover, synthesized gold and silver nanoparticles exerted anti-inflammatory and analgesic activities. ${ }^{68}$

Similarly, synthesized silver nanoparticles enhanced the anti-inflammatory, antioxidant, anti-diabetes, and antibacterial activities of some extracts. ${ }^{69}$ Besides, silver nanoparticles produced by plant extracts diminished in vivo carrageenan-induced oxidative stress and inflammation responses. ${ }^{70}$ In addition, green synthesis of silver nanoparticles $^{71,72}$ and Terminalia species leaves extract ${ }^{73}$ showed significant anti-inflammatory activity via reducing the production of cytokines and inhibiting the cyclooxygenase enzyme.

In all, nanoparticles can attenuate several inflammatory pathways and mediators towards combating NDDs.

\section{Neuroapoptosis in NDDs: Role of Nanoparticles}

Apoptosis is described as programmed cell death associated with some of the morphological changes, including the condensation of chromatin, breakdown of the nuclear membrane, cell shrinkage, and the production of apoptotic bodies. Two main pathways that trigger the apoptosis process are extrinsic that commonly known as the death receptor pathway, and mitochondrial or the intrinsic pathway. ${ }^{14}$ The intrinsic pathway of apoptosis is started within the cell, which leads to increasing the activation and expression of $\mathrm{BH} 3$-only proteins, consequences in the activation of the Bax. In some cells, this process may be accompanied by Bak elevation that enhances the formation of mitochondrial membrane pores' construction and facilitates the releasing and extrication of cytochrome $\mathrm{c}$ to bind apoptotic peptidase activating factor-1 (APAF-1). Caspase activation results from this cascade that enhances cleave and activates the downstream caspases and cellular protein degradation. ${ }^{14}$ The external pathway starts outside the cell and is triggered via the activation of death receptors by death ligands and activates caspase- 8 and leads to cleaves downstream caspases as well as cleaves and facilitates the activation of the BH3-only protein Bid. ${ }^{14}$ Inhibiting variant parts of the intrinsic and extrinsic apoptosis pathways can lead to significant effects and is considered a promising strategy for suppressing neuronal apoptosis. 
Despite these applications, nanoparticles have been used in several studies to enhance various compounds' in vitro and in vivo neuroprotective properties. Such technology has effectively reduced neuronal inflammation, oxidative stress, and apoptosis. ${ }^{1}$ Accordingly, Wang et al designed a new nanoparticle-mediated formulation to improve the drug delivery for protecting neurons against injury induced by cerebral ischemia/reperfusion. Nanoparticles loaded with complement components significantly diminished the microglial neurotoxicity after injury via decreasing the levels and activity of pro-inflammatory factors, inflammatory cells, and neuronal apoptosis. ${ }^{74}$ In the study of Yuan et al, treatment with selenium nanoparticles provided significant neuroprotective activity via diminishing the oxidative, inflammatory, and apoptotic cascade.

Moreover, selenium nanoparticles properly reversed the neurochemical alterations, neuronal loss, and oxidative damage in the mice model. ${ }^{75}$ In another study, antioxidant enzymes-loaded nanoparticles protected the neuronal cell against apoptosis via declining mitochondrial dysfunction in the rat model of spinal cord injury. The treatment with encapsulated CAT and SOD in biodegradable nanoparticles improved mitochondrial function, decreased cytochrome $\mathrm{c}$ activities, and inhibited the activation of caspase- 3 and cleaved caspase- 3 , ROS concentration, and neuronal activity cell apoptosis as well as lesser affected area compared to untreated animals. ${ }^{76}$ Furthermore, the combination treatment with gold nanoparticles reduced brain cell apoptosis and brain infarct volume. It enhanced the levels and concentration of several neurotrophic factors in the rats model of ischemic stroke. ${ }^{77}$ Also, using biodegradable nanoparticles diminished the edema formation, inflammatory responses, neuronal apoptosis and promoted the process of neurogenesis in infarcted rat brain. ${ }^{78}$ Accordingly, boron nitride nanoparticles provided significant neuroprotective effects versus the $\mathrm{MPP}^{+}$induced neuronal apoptosis in the in vitro model of PD. ${ }^{79}$

Thus, multiple apoptotic mediators are modulated by nanoparticles in fighting NDDs.

\section{Protein's Aggregation in NDDs: Role of Nanoparticles}

Protein and peptide aggregation into amyloid fibrils has been identified as a key cause of various protein misfolding-related disorders, including $\mathrm{AD}, \mathrm{PD}, \mathrm{ALS}$, and miscellaneous NDDs. ${ }^{3}$ Researchers discovered $A \beta$ as the significant part of brain plaques/tau protein and a central component of neurofibrillary tangles. ${ }^{80}$ In afflicted families with genetic anomalies, mutations and multiplications of $\alpha$-synuclein and $\mathrm{A} \beta$-related genes produce some kinds of NDDs. Overproduction of such proteins and their excessive aggregation has been proven in various models to neuronal malfunction and death. ${ }^{81}$ Neurofibrillary tangles are composed of intraneuronal paired helical filaments of a microtubule-associated protein (tau) that has been hyper-phosphorylated at several locations throughout the polypeptide chain.

On the other hand, amyloid plaques are extracellular aggregates whose major component is an amyloid peptide (A $\beta 40-42$ ). These amyloid plaques arise when $A \beta$ aggregates, thereby generating oligomers, protofibrils, and fibrils that are deposited in the brain. ${ }^{3}$ The primary peptide in the brain parenchyma is the $A \beta 1-42$ peptide, which is sensitive to aggregation/fibrillation, is thought to undergo metal-induced aggregation response, and finally produces plaques. In this way, nanoparticles play an important role with their anti-amyloid properties. ${ }^{3}$

$\mathrm{AD}$ is considered a common form of dementia characterized by memory loss, cognitive impairment, and behavioral problems. $\mathrm{AD}$ is a protein misfolding-based disorder caused by the aggregation and misfolding of tau and $\mathrm{A} \beta$ peptides, leading to neurofibrillary tangles and amyloid plaques, respectively. ${ }^{82,83}$ The results of two sequential cleavages of amyloid precursor protein are a transmembrane protein with 42-residue known as $A \beta$ that does not play a specific physiological role. ${ }^{82,83}$ Increased concentration of immature autophagic vacuoles in neurons is associated with elevating the production of autophagic core agents, spoiled fusion with lysosomes, and retrograde transportation of autophagosomes that facilitate the accumulation of pathogenic $A \beta{ }^{82}$ Tau phosphorylation, located primarily in neurofibrillary tangles, is another hallmark of $\mathrm{AD}^{82,84}$

Further, a mutant form of the nerve terminal protein, $\alpha$ synuclein, is a significant pathogen of PD. The function of mutant $\alpha$-synuclein as the main autosomal dominant promoted several point mutations accompanying the PD (eg, E46K, A30P, and A53T) that lead to rendering the aggregation and misfolding of $\alpha$-synuclein prone. The formation and development of intracellular inclusions named Lewy bodies (LBs) result from aggregation and accumulation of mutant $\alpha$-synuclein that are a hallmark of familial and sporadic PD. ${ }^{82,85,86}$ ALS is another debilitating neurodegenerative disease that loses neurons responsible for 
controlling voluntary muscles. Signs and symptoms play a significant role in diagnosing a person and tests that eliminate other possible reasons. It was reported that mutations in the chromosome encoding SOD, chromosome 21, have been implicated as a major cause in $2 \%$ of all cases and $20 \%$ of familial cases with ALS. $^{82}$ Over one hundred diverse mutations have been identified with this mutation, which is thought to be transmitted autosomal dominantly. Mutation of the SOD1 gene is the most common cause of ALS, frequently occurring in North America; this level of mutation is characterized by an exceptionally rapid onset and progression of the disease. Scandinavians are more likely to have the mutation D90A-SOD1 than people living with typical ALS. It is more slowly progressing than typical ALS, and people with this mutation live an average of 11 more years. ${ }^{87-89}$ In addition to the SOD1, vesicleassociated protein $\mathrm{B}$ (VAPB), tank binding kinase 1 (TBK1), Ubiquilin-2, tar DNA binding protein-43 (TDP43), valosin containing protein (VCP), p62, and fused in sarcoma (FUS) are other misfolded proteins involve in pathologically of ALS. ${ }^{90,91}$

In addition, tau protein, huntingtin with tandem glutamine repeats, prion proteins, and transthyretin (mutant forms) are other essential aggregated proteins related and associated with several neurodegenerative diseases including multiple neurodegenerative disease tauopathies, HD, spongiform encephalopathies, and familial amyloidotic polyneuropathy, respectively. ${ }^{82,92}$ Misfolded disease proteins exert toxic effects by interfering with several pathways and strongly binding to the biological membranes, such as mitochondrial membranes, plasma, and other cytosolic protein membranes. ${ }^{92,93}$ This process results in the distortion and loss of membrane integrity and leads to ROS production, $\mathrm{Ca}^{2+}$ influx aberrant, and the alteration of variant signaling pathways, which facilitated cell death. $^{92,93}$ For instance, mutant tau disrupts neuronal transport mechanisms and microtubule function, and $\alpha$ synuclein, tau, and $A \beta$ lead to interference with synaptic signaling. Moreover, mitochondrial protein transport disruption is another $\alpha$-synuclein toxicity mechanism. The nucleocytoplasmic transport of proteins and RNA has also been disrupted by cytosolic aggregates of several other proteins, including mutant huntingtin, artificial $\beta$ sheets, and TDP-43. ${ }^{92-94}$ Targeting these proteins can be a valuable and significant strategy for preventing and treating neurodegenerative diseases. Various drugs have been approved or investigated in different phases of clinical studies, including istradefylline, deferiprone, arimoclomol, nuedexta, AADvac1, and TRx0237, targets this protein. ${ }^{92}$

Dysregulated signaling pathways in NDDs are presented in Figure 1. Besides, the role of nanoparticles in combating NDDs-associated neuroinflammation, neuronal oxidative stress, neuroapoptosis and protein aggregation is provided in Figure 2.

\section{Dual Function of Nanoparticles; Neurotoxicity Potential of Nanoparticles via Induction of Apoptosis, Oxidative Stress, and Inflammation}

As mentioned, nanoparticles have shown significant beneficial activities and promoted increasing effects, bioavailability, half-life, stability against degradation in the CNS. Such effects enhance the efficacy, reduce dosage and side effects of these structures in the treatment of NDDs. ${ }^{1,31}$ Despite these practical effects, nanoparticles have also shown a severe triggering effect on inflammation, apoptosis, necrosis, autophagy, and oxidative stress processes, which may promote the potential of chronic and acute human health risks ${ }^{95}$; however, the systematic clinical studies and detailed documented reports that nanoparticle-induced toxicity in humans is limited. Several studies analyzed the toxicity potentials of nanoparticles in animal models and cell culture. ${ }^{96}$ Therefore, increasing our understanding and knowledge of the toxicity mechanisms of these structures is essential and helps to provide new strategies for designing, producing, and utilizing suitable nanoparticles for safer use of nanotechnology in humans. ${ }^{95}$ Neurotoxicity, pulmonary toxicity, genotoxicity, and immunotoxicity are some of the most important examples of reported human toxicity induced by nanoparticles. ${ }^{95}$ The nanoparticle-induced toxicity may be related to dosage, frequency of use, concentration, and time of exposure, as well as the routes of administration. ${ }^{95}$ Also, shape, particle size, charge, roughness, surface coating, and composition are other parameters that affect nanoparticles toxicity. ${ }^{97}$ The production of variant ROS including hydroxyl radicals, singlet oxygen, peroxide ions, oxygen radicals, superoxide anion radicals, and hydrogen peroxide $(\mathrm{H} 2 \mathrm{O} 2)$ was introduced as the main nanotoxicity mechanism that may occur in various ways. ${ }^{95,98}$ ROS generation, inducing oxidative stress, membrane perturbation, DNA damage, cytoskeletal dysfunction, direct physical damage, enzyme dysfunction, blocking the cell membrane channels 


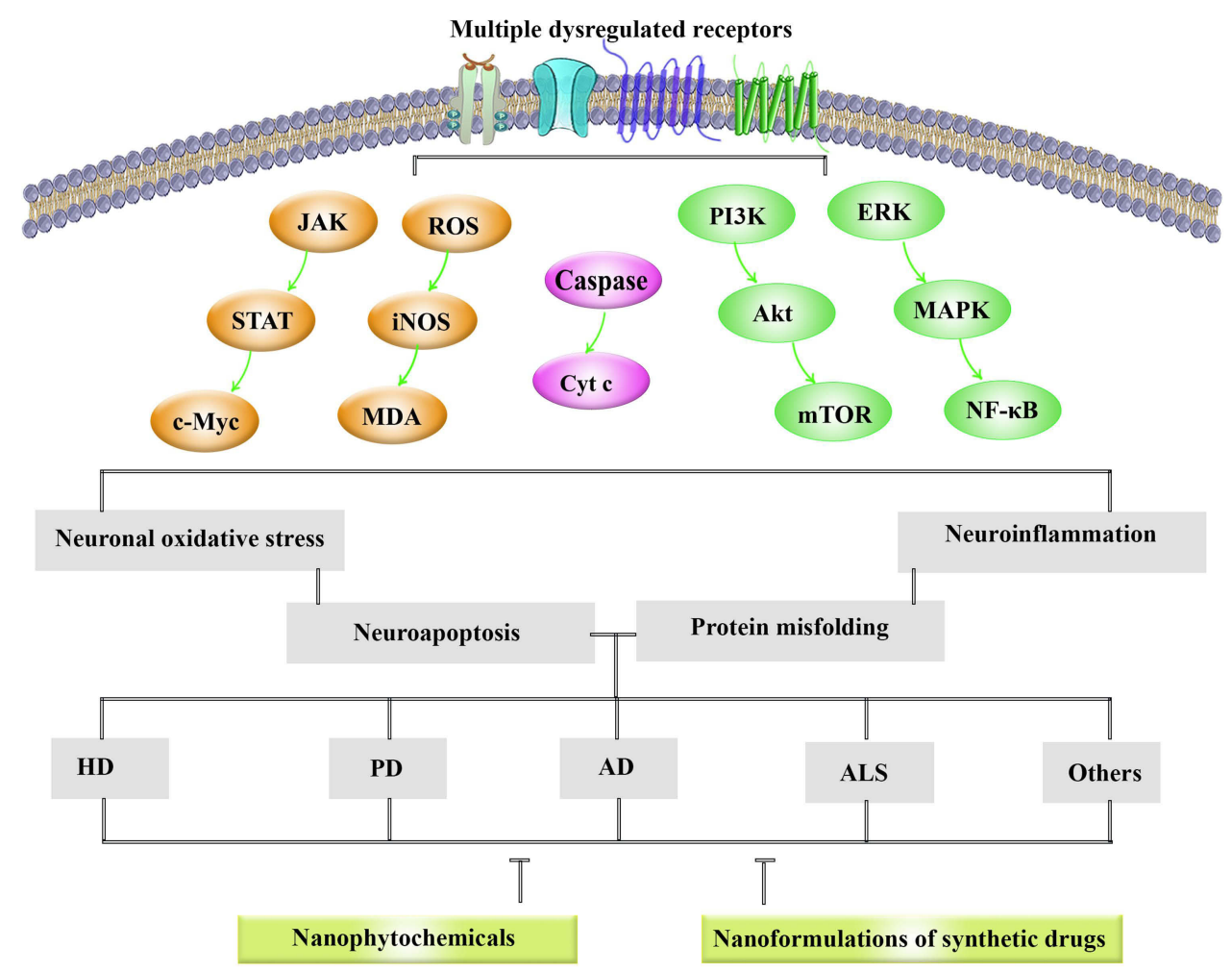

Figure I Dysregulated signaling pathways in NDDs.

Abbreviations: AD, Alzheimer's disease; ALS, amyotrophic lateral sclerosis; Cyt c, cytochrome c; ERK, extracellular signal-regulated kinase; HD, Huntington's disease; iNOS, inducible nitric oxide synthase; JAK, Janus kinase; MAPK, mitogen-activated protein kinase; mTOR, mammalian target of rapamycin; NF- $\mathrm{kB}$, nuclear factor kappa-lightchain-enhancer of activated B cells; PD, Parkinson's disease; PI3K, phosphoinositide 3-kinases; RNS, reactive nitrogen species; ROS, reactive oxygen species; STAT, signal transducer and activator of transcription.

and receptors, abnormal morphological stretching, and protein misfolding were reported as the main toxicity mechanism of nanoparticles. ${ }^{97-100}$ The oxidative reaction of an electron with nanoparticle's surface groups or transition metals is another reported mechanism of ROS production. Enhancing the surface area leads to an augmentation of chemical reactivity potentially and ROS production. Nanoparticles can promote mitochondrial membrane damages.

For this reason, mitochondrial respiration and penetration of ROS from perforated mitochondrial membranes into the cytoplasm is another mechanism of ROS production. ${ }^{95,101,102}$ The elevated intracellular ROS levels lead to more ROS releases from mitochondria and amplify the oxidative imbalance and oxidative stress that promoted damage to the DNA, cellular organelles, ion channels, receptors, and cell membranes, which accelerate more adverse effects and toxicity. ${ }^{95}$ In addition, released harmful metal ions and ROS can interfere with variant signaling pathways including protein kinase B (Akt), Src, MAPK, NF- $\mathrm{B}$, and HIF that cause influence cell survival, proliferation, and differentiation. ${ }^{95,103}$

Several other studies have investigated the neurotoxicity of various nanostructures. The intravenous injection of polysorbate 80 -modified chitosan nanoparticles leads to the accumulation of nanoparticles in the cerebellum, frontal cortex, oxidative stress elevation, inflammatory process activation, and neuronal apoptosis in treated rats. ${ }^{104}$ Moreover, it was reported that direct administration of the liposomal formulation of cisplatin into the brain might lead to highly neurotoxic advantages due to the intrinsic neurotoxic effects of liposomes in combination with cisplatin. ${ }^{105}$ Also, exposure to the polyamidoamine dendrimers provided a charge surface-dependent in vitro neurotoxic activity and increased the DNA damage, apoptosis, oxidative stress, and suppressed neuronal differentiation and mitochondrial function in neural cells. ${ }^{106}$ Treatment with iron oxide nanoparticles prompted oxidative stress, enhanced iron accumulation, and facilitated protein aggregation in the neural cells. ${ }^{107}$ Also, induction of oxidative stress was reported as the primary 


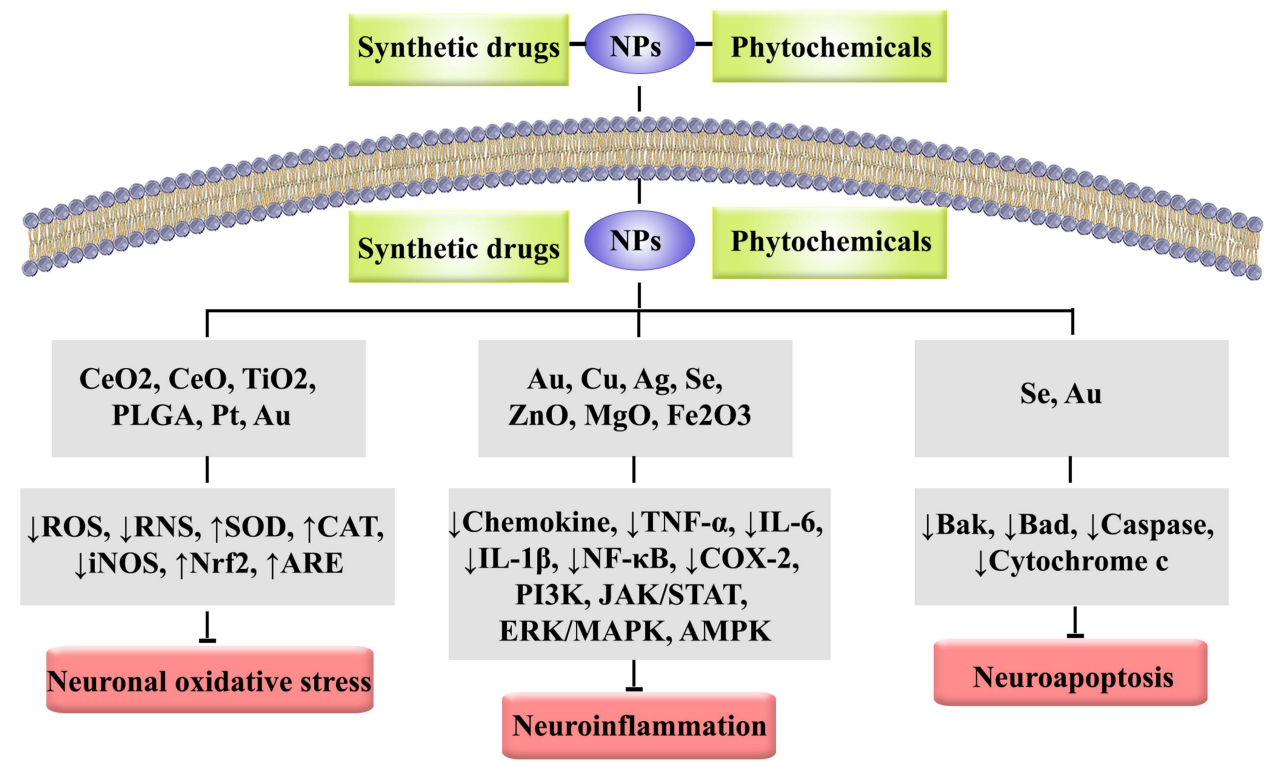

Figure 2 The role of nanoparticles in combating NDDs-associated neuroinflammation, neuronal oxidative stress, and neuroapoptosis.

Abbreviations: Ag, silver; AMPK, AMP-activated protein kinase; ARE, antioxidant response element; $\mathrm{Au}$, gold; CAT, catalase; CeO, cerium oxide; CeO2, cerium dioxide; COX, cyclooxygenase; Cu, copper; ERK, extracellular signal-regulated kinase; Fe2O3, Iron oxide; IL, interleukin; iNOS, inducible nitric oxide synthase; JAK, Janus kinase; MAPK, mitogen-activated protein kinase; MgO, magnesium oxide; NF- $\mathrm{BB}$, nuclear factor kappa-light-chain-enhancer of activated B cells; NPs, nanoparticles; Nrf2, nuclear factor-erythroid factor 2-related factor 2; PI3K, phosphoinositide 3-kinases; PLGA, poly(lactic-co-glycolic acid); Pt, platinum; RNS, reactive nitrogen species; ROS, reactive oxygen species; Se, selenium; SOD, superoxide dismutase; STAT, signal transducer and activator of transcription; TiO2, titanium dioxide; TNF- $\alpha$, tumor necrosis factor-alpha; $\mathrm{ZnO}$, zinc oxide.

neurotoxicity mechanism of silver nanoparticles in the exposed rat's cerebral astrocytes. ${ }^{108}$ Furthermore, the in vivo and in vitro investigation of neurotoxicity mechanisms of silica nanoparticles showed the induction of neuropathology, MAPK activation, and behavior changes in mice and cultured neurons. ${ }^{109}$ Silica and gold nanoparticles also represent a new class of delivery systems to multi-drug resistance into neurons to treat future brain disease. $^{110}$ Oxidative stress, genotoxicity, inflammatory response, apoptosis, dysregulation of neurotransmitters, and to a lesser extent, DNA methylation and autophagy have been considered possible neurotoxicity mechanisms of TiO2 nanoparticles. ${ }^{111}$ Cadmium telluride quantum dots exerted neurotoxicity effects on motor neurons via induction of oxidative stress. ${ }^{112}$ Moreover, acceleration of autophagy process, elevating levels of cytoplasmic $\mathrm{Ca}^{2+}$, and impairments of synaptic transmission are reported as the primary other in vivo and in vitro neurotoxicity mechanisms of the quantum dot. ${ }^{113}$

\section{Overcoming the BBB by Nanoparticles, as an Attractive, and Effective Strategy}

The inability of most therapeutic compounds to sufficiently cross the blood-brain barrier (BBB) diminishes the potential of treatment tools for NDDs. It makes the $\mathrm{BBB}$ one of the main limitations of progress in the treatment of NDDs. The BBB is composed of an evolved from the brain microvascular system, which acts as an effective membrane barrier that separates circulating blood from the brain's extracellular fluid in most vertebrate species. ${ }^{114-117}$ The BBB consists of the basal lamina, which comprises various extracellular matrix proteins, including collagen, heparan sulfate, and laminin that surround pericytes and microvessel endothelial cells. ${ }^{114,116}$ Astrocyte endfeet and interneurons are other structures present in the construction of BBB. The BBB already contains gap junctions, tight junctions, and adherens junctions. Still, tight junctions appear to be more important than the other types of connections in the BBB because they cause high levels of electrical resistance between the endothelial cells. ${ }^{114,115}$ The prominent role of $\mathrm{BBB}$ is the protection of the brain from all foreign agents. BBB also supported the brain from alterations of ionic composition in the cerebrospinal fluid and facilitated the metabolizing of variant chemical compounds and disposing of waste products. ${ }^{115,116}$ The disruption of the extracellular matrix proteins can increase the BBB permeability, which assists and improves the drug's transportation. Nanoparticles generally cross the BBB through two mechanisms, including passive and active 
transfer pathways. Accordingly, gold nanoparticles and small lipophilic molecules $(<400 \mathrm{Da})$ could pass through the BBB in a passive transfer system. ${ }^{115,116,118}$ In addition, active endocytosis is mediated by receptor, carrier, and adsorption strategies. Receptor-mediated endocytosis facilitates the penetration of various nanostructures such as liposomes and PLGA based nanoparticles from BBB. ${ }^{116,119,120}$ The receptors responsible for active influence include low-density lipoproteins, transferrin, lactoferrin, insulin receptors, and their ligands. ${ }^{115-117}$ The process of nanoparticles transportation by adsorption to endothelial cells is mediated by the surface properties of the nanoparticles. As the plasma membrane of endothelial cells is negatively charged, the cationic nanoparticles are more likely to undergo this mechanism than negatively charged or neutral ones. Liposomes and gold nanoparticles can cross the BBB using such method. ${ }^{116}$ An additional mechanism of nanoparticles for enhancing drug delivery across the $\mathrm{BBB}$ is carrier-mediated transport pathways such as the glucose transporter 1 (GLUT1) protein and the amino acid transporter (ASCT2). ${ }^{116}$

\section{Nanoformulations in Combating Neurodegeneration: Pre-Clinical Evidence}

Pharmaceutical studies have recently concentrated on advancing nanotechnology methods relevant in several medicine sectors, including drug delivery. ${ }^{31}$ As a result, it is necessary to develop novel ways to enhance the effectiveness, transport throughout the BBB, bioavailability, and ultimately the negative impact of pharmacological substances used to treat NDDs. ${ }^{121}$ Applying nanoparticles to transport therapeutic substances enhances biodistribution and pharmacokinetics, permits co-delivery of several drugs, provides targeted intracellular drug delivery and decreases systemic toxicity/side effects. ${ }^{122}$

\section{Alzheimer's Disease and Nanoformulation}

$\mathrm{AD}$ is the primary cause of dementia, a clinical condition marked by a gradual decrease in two or more general cognitive, such as dysfunctionalities in cognition, language, executive/visuospatial activity, personality and behavior, resulting in a loss of ability to execute instrumental and/or fundamental activities, and the most common neurodegenerative condition. ${ }^{123}$ It is generally diagnosed after 3-6 years of amnestic moderate cognitive problems. The brains of AD patients show the existence of extracellular $A \beta$ plaques and intraneuronal tau-containing neurofibrillary tangles cross-talked to inflammatory/oxidative stress/apoptotic pathways. ${ }^{124}$ The presence of BBB is a critical issue in the treatment of neurological disorders because it prevents many medicines from entering the brain in adequate concentration. ${ }^{19}$ So, we need nanomedicine therapy to overcome such issues.

\section{Alzheimer's Disease and Phytochemicals Nanoformulations}

The plant kingdom and associated phytochemicals have shown promising anti-AD effects. ${ }^{10}$ As a natural polyphenolic compound, resveratrol is found in grapes, mulberries, peanuts, rhubarb, and wines. It has been shown to depolymerize $A \beta$ peptides via a proteasome function; however, it does not impact $\beta$ - and $\gamma$-secretase enzymes and transthyretin, a sequesters protein amyloid protein. Several findings showed the potential of resveratrol against tauopathy associated with $\mathrm{AD}$, demonstrating a decrease in tau levels in rats and suppression of tau hyperphosphorylation/ accumulation. $^{121}$ However, there are some pharmacokinetic limitations in its application. ${ }^{125}$ Considering the resveratrol's quick clearance from the bloodstream, solid lipid nanoparticles (SLNs) were designed to encapsulate and carry the extracts into the brain, where amyloid fibril production occurs. SLNs are a viable, dynamic mechanism for delivering resveratrol to the brain in an area and avert/ slow $\mathrm{AD}$ development by inhibiting the production of $\mathrm{A} \beta$ (1-42) aggregates. ${ }^{126}$ Also, the in vivo evaluation showed that designed nanostructured lipid carriers (NLCs), delivered nasally, may successfully combat AD compared to an orally supplied resveratrol solution. The better memory function and enhanced permeation across nasal mucosa recommend that the resveratrol NLC-based in situ gel could efficiently decrease the crystallinity of particles through the lipid-oil mixture and convenient strategy for the treatment of AD. ${ }^{127}$

As another phenolic compound, curcumin, which is gained from Curcuma longa, has beneficial effects in treating NDDs; however, low bioavailability, a fast metabolism, and quick elimination of curcumin limited its efficacy. ${ }^{128}$ Curcumin's primary product, responsible for its neurotherapeutic effectiveness, exerts through a decrease in $A \beta$ peptide aggregation. It also reduced $A \beta$ induced oxidative damage and neuroinflammation by using nanoformulation. Continuously, nanocurcumin prevented the formation and neurotoxicity of two $\mathrm{AD}$ 
markers, hyperphosphorylated tau and amyloid misfolding. ${ }^{129}$ Furthermore, it controls several aspects of the $\mathrm{AD}$, such as binding copper, decreasing cholesterol levels, regulating microglial function, inhibiting acetylcholinesterase, upregulating the insulin signaling pathway, and acting as an antioxidant. ${ }^{130}$ Even at modest doses, nanocurcumin improved working and recall memory in a mice AD model. Besides, curcumin bioavailability was considerably enhanced by the nanoparticle formulation, according to pharmacokinetic tests. ${ }^{129}$

Using curcumin nanoformulation also increased its solubility and stability, propelling it to the forefront of medicinal uses. Additionally, nanocurcumin nanoparticles are more stable than native curcumin under physiological circumstances. Accordingly, PLGA-nanoparticles offered an effective curcumin delivery method to defend human neuronal cells from oxidative damage, as shown in AD. ${ }^{131}$ Curcumin encapsulated in PLGA nanoparticles with a ligand for $\mathrm{BBB}$ crossing demonstrates minimal toxicity and a substantial reduction in $A \beta$ aggregates. Consequently, brain administration of nanocurcumin through $\mathrm{BBB}$ crossing is a potential future strategy in treating AD. ${ }^{132}$

Curcumin-encapsulated in PLGA (Cur-PLGA) nanoparticles, particularly compared to bulk curcumin, promoted proliferation of endogenous neural stem cells and neuronal differentiation in vitro and in the hippocampus and subventricular zone in vivo. Curcumin nanoparticles stimulate proliferation at smaller concentrations and are not toxic at high doses. In an AD rat model, Cur-PLGA nanoparticles restored mediated inhibition on hippocampus neurogenesis, cognition, and memory via activating the canonical Wnt/ $\beta$-catenin pathway. ${ }^{133}$ For the treatment of AD, PLGA-poly(ethylene glycol) (PLGA-PEG) conjugated with B6 peptide-loaded with curcumin (PLGA-PEG$\mathrm{B} 6 /$ Curcumin) might be a viable option in vitro through reducing curcumin size, enhancing its cellular absorption, and also blood compatibility. The results showed a significant increase in spatial learning and memory performance of APP/PS1 mice compared to native curcumin. Besides, ex vivo studies revealed that PLGA-PEG-B6/Curcumin decreased hippocampus $A \beta$ production and deposit, as well as tau hyperphosphorylation. ${ }^{134}$

As another novel formulation of curcumin, nanoliposomes were found to be stable and monodispersed. Those formulations were safe in vitro, inhibited amyloid peptide production, and partly reduced $A \beta$-induced toxicity. They found deposits in post-mortem brain tissue from $\mathrm{AD}$ patients and mice following treatment with nanoliposomes. ${ }^{135}$ Curcumin can bind tau protein-based amyloid by in vivo and in vitro models of AD. It exhibited anti-amyloid effects at micromolar doses. Curcumin was also found to be capable of inhibiting tau protein hyperphosphorylation. Curcumin-encapsulated PLGA nanoparticles could eliminate amyloid aggregates, thereby showing antioxidative, with no cytotoxic effect. ${ }^{3}$

Naringenin is a flavonoid that protects neurons from free radicals and inflammation but has a poor capacity to penetrate biomembranes. The naringenin-loaded nanoemulsion significantly decreased the direct toxic effect of $\mathrm{A} \beta$ on SH-SY5Y cells, which was linked with a decrease in the expression of APP, $\beta$-secretase, and attenuating amyloidogenesis. In SH-SY5Y cells exposed to $\mathrm{A} \beta$, it also reduced the amounts of phosphorylated tau. These findings implied that naringenin-loaded nanoemulsion might be a potential method for treating AD. ${ }^{136}$

As another phytochemical, quercetin has shown potential therapeutic roles against NDDs. The limited oral bioavailability of quercetin restricted its medicinal use. As a possible oral therapy for $\mathrm{AD}$, nanoencapsulated quercetin in zein nanoparticles dramatically increased oral absorption and bioavailability of the flavonoid. Treatment with such orally used flavonoid enhanced the cognitive and memory deficits of SAMP8 mice. ${ }^{137}$ When quercetin was incorporated into -cyclodextrin-dodecyl carbonate nanoparticles, its anti-inflammatory actions via diminishing the toll-like receptor 4 (TLR4) and COX-2 signaling pathway on SH-SY5Y cells were increased compared to cells treated with free quercetin. The objective of encapsulating quercetin in nanoparticles was to enhance its penetration through the BBB and bioavailability, preventing or decelerating the progression of AD. ${ }^{138}$ Palle and Neerati also showed that pretreatment of rats with quercetin nanoparticles reduced scopolamine-induced behavioral alterations, suggesting that it might be used as a preventative approach against the advancement of AD. In such experimental models, quercetin nanoparticles outperformed quercetin, implying that the enhanced effectiveness is related to a more extended residence period in the systemic circulation and higher bioavailability. ${ }^{139}$

The genesis of $\mathrm{AD}$ has been linked to the dysfunctional interaction of $\mathrm{A} \beta$ with excess metal ions. As a result, employing nanoparticles to disturb these metal-peptide connections holds much potential as a treatment method. In vitro investigations showed that PLGA-functionalized quercetin nanoparticles have minimal cytotoxicity and, 
therefore, can prevent the neurotoxicity of the $\mathrm{Zn}^{2+}-\mathrm{A} \beta 42$ system while also increasing neuron cell survival by suppressing the $\mathrm{Zn}^{2+}-\mathrm{A} \beta 42$ system. Administration of PLGAfunctionalized quercetin nanoparticles in APP/PS1 mice improved cognitive functions and memory, according to data from in vivo investigations. ${ }^{140}$

Polyacrylamide-chitosan-PLGA nanoparticles with CRM197 and apolipoprotein E (ApoE) nanoparticles were created to slow the degeneration of $A \beta$-insulted neurons, improve rosmarinic acid transportation throughout the $\mathrm{BBB}$, and boost antiapoptotic impact via blocking the production of caspase-3 and c-Jun parameters on SK-NMC cells. Such nanoparticles have the potential to be an important route of administration for brain-targeting behavior and have neuronal restoration in $\mathrm{AD}$ therapy. ${ }^{141}$

The antioxidant effects of epigallocatechin 3-gallate (EGCG), the main catechin found in tea, are well documented. It can enhance the non-amyloidogenic processing of APP via increasing the expression of $\alpha$-secretase, therefore reducing the development of brain $A \beta$ plaques, a characteristic of $\mathrm{AD}$ pathogenesis. The potential of EGCG nanolipidic particles enhanced neuronal $\alpha$-secretase in vitro by up to $91 \%$ and its oral bioavailability in vivo by more than two-fold over free EGCG. ${ }^{142}$ Anti-amyloidogenic, metal chelation, and antioxidant activities of EGCG have been demonstrated. NanoEGCG antioxidant and metal chelation capabilities outperformed its free form and significantly reduced cellular toxicity.

Furthermore, an in vitro study demonstrated that EGCG nanoparticles could prevent $\mathrm{Al}^{3+}$-induced $\mathrm{A} \beta 42$ fibrillation and neurotoxicity. ${ }^{143}$ In another study, EGCG was bonded to the surface of selenium nanoparticles to decrease the cytotoxicity of EGCG at significant concentrations. EGCG-selenium nanoparticles were synthesized, given the affinity of peptide to neurons, due to the poor delivery efficiency of EGCG-selenium nanoparticles to the targeted cells. The role of selenoprotein in antioxidation and neuroprotection is essential in limiting the initiation and progression of AD. EGCG-stabilized selenium nanoparticles coated with peptides inhibited $A \beta$ fibrillation and efficiently disaggregated $A \beta$ fibrils into harmless aggregates. Furthermore, EGCG-selenium nanoparticles showed a strong affinity for labeling $A \beta$ fibrils. ${ }^{144}$

Sesamol, a polyphenolic substance, is the main component of sesame seed oil (Sesamum indicum L). ${ }^{145}$ When the pure sesamol and sesamol-SLN groups were compared, the latter group was much more effective than the pure sesamol group at $16 \mathrm{mg} / \mathrm{kg}$ dosage, which was nearly comparable to the rivastigmine impacts. Our findings showed that putting sesamol in the SLNs is an excellent approach for reducing intracerebroventricular streptozotocin-induced neuronal malfunction and memory impairments by lowering oxidative stress. ${ }^{146}$ Sesamol is an antioxidant-rich substance derived from the oil of Sesamum species that may play a preventive function in age-related NDDs such as AD. SLNs are excellent delivery vehicles for transporting sesamol to the CNS; they can be investigated as a brain targeting approach for AD. SLNs were found to successfully repair cognitive impairments in rats given intracerebroventricular streptozotocin, as well as alleviating oxidative stress measures including nitro-oxidative stress and cytokine production in an in vivo research on AD-induced model. ${ }^{124}$ As another phenolic compound, ferulic acid showed high antioxidant action against AD. Pure SLN demonstrated zero toxicity on human neuroblastoma cells (LAN 5) at the doses tested, as well as the capacity to enter these cells. Furthermore, cells treated with ferulic acid-loaded SLN produced less ROS than those treated with free ferulic acid. ${ }^{149}$

In addition to the phenolic compounds, alkaloids are another class of phytochemicals whose nanoformulations have shown hopeful neuroprotective effects. Berberine is an isoquinoline alkaloid used to manage NDDs, especially dementia, for centuries. ${ }^{147}$ Berberine-loaded multiwalled carbon nanotubes are a tremendous nanostructured construct for delivering berberine throughout the BBB. Furthermore, the phospholipid-coated and polysorbatecoated multiwalled carbon nanotubes demonstrated excellent memory function recovery in line with the capacity for transferring neuropharmaceutical agents to brain microglial cells. The ability of these nanotubes to maintain normal biochemical levels in brain tissue indicated their promise for decreasing $\mathrm{A} \beta$-induced $\mathrm{AD} .{ }^{148}$

In addition to phenolic compounds and alkaloids, terpenoids are also promising candidates against NDDs. A sesquiterpene huperzine A (HupA)-loaded, mucoadhesive, and targeted PLGA nanoparticles with surface modification by lactoferrin-conjugated N-trimethylated chitosan nanoparticles are used for effective intranasal transport of huperzine $\mathrm{A}$ to the brain for the treatment of AD. The significant mucoadhesion of such nanoparticles was shown by in vitro mucin adsorption. The regulated drug release was validated by ex vivo drug release and cell survival tests utilizing the $16 \mathrm{HBE}$ cell line. Thus, the active targeting of lactoferrin and the mucoadhesion of trimethylated chitosan nanoparticles were widely dispersed in the brain 
over a long time. ${ }^{149}$ As triterpenoids, ginsenosides are other phytochemicals with neuroprotective mechanisms. A new nanotherapeutic approach that increases ginsenoside distribution to the brain by boosting BBB permeability might aid neuroprotective effects and minimize the formation of $\mathrm{A} \beta$ plaques and eventual neurodegeneration. For the diagnosis and treatment of AD, PLGA-ginsenoside Rg3 nanoparticles offered an intriguing novel theranostic material suitable of encapsulating natural nutraceuticals. ${ }^{150}$

Therefore, the nanoformulations of phytochemicals (eg, resveratrol, curcumin, naringenin, quercetin, rosmarinic acid, EGCG, ginsenoside, ferulic acid, berberine, huperzine, and sesamol) of different classes (eg, phenolic compounds, alkaloids, and terpenoids) have shown therapeutic effects on $\mathrm{AD}$ by modulating multiple dysregulated pathways. In this line, nanophytochemicals critically inhibit the aggregation and production of protein misfolding, modulate neuroinflammatory, neuroapoptosis, and neuronal oxidative stress. Additionally, nanophytochemicals improve the bioavailability of secondary metabolites and reduce cellular toxicity by affecting the pathways mentioned above.

\section{Alzheimer Disease and Nanoformulations of Synthetic Drugs}

Several synthetic formulations are employed in combating $\mathrm{AD}$; however, nanoformulations seem to increase their efficacy. As a hematopoietic factor, erythropoietin (EPO) is a potential neuroprotective agent in AD by promoting neuronal survival and controlling neurogenesis. However, the transfer of EPO to the CNS is complicated and occurs at deficient levels because of its large molecular weight, hydrophilicity, and fast blood elimination. This way, Dara et al created EPO-loaded SLN to alleviate the restrictions mentioned above. ${ }^{151}$ In vivo studies showed that EPO-SLN could protect the animals' brains from damage caused by an intra-hippocampal injection, with spatial recognition memory considerably recovered compared to rats treated with free EPO. Another synthetic drug, nicotinamide, a histone deacetylase blocker demonstrated in preclinical trials to be beneficial in stopping AD, has poor absorption. This hydrophilic medication was encapsulated in SLN, who functionalized the nanocarriers using polysorbate 80, phosphatidylserine, or phosphatidic acid. ${ }^{151}$ When compared to traditional oral nicotinamide, the phosphatidylserine-SLN was efficient in conveying and distributing nicotinamide to the brain in a sustained manner, supposed to lead to cognition enhancement, protection of more neuronal cells (higher neuronal counts in hippocampus subregions) and decrease of tau hyperphosphorylation in an AD rat model.

According to the findings, the liposomes formulation of rivastigmine (an acetylcholinesterase inhibitor) contributed to quicker memory recovery and improved metabolic abnormalities in $\mathrm{AlCl} 3$-treated rats. The rivastigmine liposomes nano-based formulation outperformed traditional drug solutions in terms of sustained release and patient compliance, suggesting it to be a promising drug delivery method for treating AD. ${ }^{152}$ Another research showed that rivastigmine SLN, while lipidic, demonstrated more drug diffusion than a drug solution containing a crystalline form of the drug. Rivastigmine SLN did not affect nasociliary disruption or cell necrosis, showing that it is acceptable for nasal administration. ${ }^{153}$ The liposomal preparation of donepezil (another acetylcholinesterase inhibitor), a prototype anti-AD medication, was resilient and exhibited sustained-release characteristics. Compared to the traditional dose form and method of administration, intranasal delivery of donepezil liposomes dramatically improved the drug's brain bioavailability. Furthermore, this method allows patients to self-administer medications painlessly and simply. ${ }^{154}$ Continuing to the drugs of this class, galantamine hydrobromide, an acetylcholinesterase inhibitor, poorly penetrates the brain. To solve these constraints, the SLN formulation of galantamine hydrobromide was created. In vivo tests revealed substantial memory restoration potential in cognitive deficit rats compared to an uninformed medication; SLN provided the bioavailability of the standard medicines. ${ }^{155}$

Memantine (an NMDA blocker), authorized for $\mathrm{AD}$ treatment, was incorporated into biodegradable PLGA nanoparticles generated using a double emulsion technique and had a PEG surface coating to target the BBB when taken orally. The in vitro and in vivo data for brain drug levels revealed that the devised methods transport the medication to the target tissue throughout time and the decrease of $A \beta$ plaques. ${ }^{156}$ Endogenous estrogen deficiency following menopause has been linked to the development of $\mathrm{AD}$ in postmenopausal women. ${ }^{157}$ In an ovariectomized rat AD model, orally given tween 80coated PLGA nanoparticles carrying estradiol resulted in substantially greater brain estradiol levels after 24 hours than unmodified ones. ${ }^{158}$

Tarenflurbil is an A $\beta 42$ selective reducing agent, and the $\gamma$-secretase modulator demonstrated encouraging outcomes in vitro and in vivo. A Phase II clinical study on 
210 patients with mild $\mathrm{AD}$ found that the drug was well tolerated, with improved performance decline in primary endpoints. ${ }^{159}$ Tarenflurbil's limited brain penetration was one of the chief factors for its defeat in Phase III clinical studies on Alzheimer's patients. As a result, there is an urgent need to create effective Tarenflurbil delivery methods. It was loaded into two types of nanocarriers, PLGA nanoparticles, and SLNs. Such nanoparticles demonstrated acceptable brain biodistribution patterns. The pharmacokinetic behavior was enhanced by using nanoparticles rather than solution/suspension. ${ }^{160}$

For transport via the BBB, n-butyl-cyanoacrylate nanoparticles can be utilized to contain clioquinol, a quinolone derivative capable of solubilizing plaques that develop in the neocortex in extracellular synaptic gaps during the start of $\mathrm{AD}$ in humans. ${ }^{161}$ As another synthetic agent, the administration of essential fibroblast growth factor (bFGF) into the hippocampus may protect neuronal degeneration and improve learning impairments in AD rats. After intranasal treatment, Solanum tuberosum lectin coupled PEG-PLGA nanoparticles may efficiently promote direct transport of bFGF into the rat brain with decreased peripheral adverse reactions. ${ }^{162}$

Altogether, nanoformulations of synthetic drugs, like erythropoietin, nicotinamide, rivastigmine, donepezil, memantine, estradiol, tarenflurbil, galantamine, clioquinol, and bFGF have shown different effects on AD through increasing neurogenesis, improving bioavailability, reducing the aggregation of proteins and attenuating dysregulated inflammation/apoptosis/oxidative stress. The preclinical evidence on using nanoformulations of synthetic drugs against $\mathrm{AD}$ is presented in Table 1.

\section{Parkinson's Disease and Nanoformulations}

Parkinson's disease (PD) is a neurological disease caused by the progressive loss of dopaminergic neuronal cells in the substantia nigra (SN) pars compacta area of the basal ganglia. Oxidative stress, inflammation, and apoptosis are the main pathophysiological characteristics of $\mathrm{PD}{ }^{130}$ It is thought that $\mathrm{PD}$ has a significant hereditary connection, with mutations in the gene $\alpha$-synuclein, which encodes for a protein that has been recognized as one of the contributing reasons for the beginning of $\mathrm{PD} .{ }^{20}$

\section{Parkinson's Disease and Phytochemicals Nanoformulations}

We have previously introduced several phytochemicals in combating PD. ${ }^{163}$ Resveratrol nanoparticles can sustain their blood levels for a longer time, improving bioavailability and, thus, pharmacological impact. As a result, resveratrol nanoparticles were shown to be more effective than naïve resveratrol in dampening rotenone-induced PDlike behavioral abnormalities, biochemical and histological changes, oxidative stress induced by hydrogen peroxide, and mitochondrial dysfunction induced by rotenone and saved the functions of complex-I and tricarboxylic acid enzymes in rats. ${ }^{164}$

Resveratrol is severely hampered by the BBB, which restricts resveratrol's entry to the CNS. In vitro, magnetic targeting drug nanocarrier, Fe3O4-modified resveratrol liposomes demonstrated sustained and delayed drug release. In vivo studies revealed that such nanoparticles could efficiently penetrate the BBB and enhance drug concentration at the targeted area in the presence of an external magnetic field. ${ }^{165}$ The in vitro and ex vivo nasal mucosa penetration of resveratrol-loaded nanoemulsions for PD was relatively high. The brain tissues of the group given resveratrol nanoemulsions had lower levels of degenerative alterations and oxidative stress indicators via the antioxidant effect of resveratrol and fewer eosinophilic lesions in the positive control group according to histopathological and biochemical tests. ${ }^{166}$ Resveratrol in polysorbate 80-coated poly(lactide) [PLA] nanoparticles can provide neuroprotection against behavioral and biochemical properties. These findings suggested that resveratrol-loaded PLA nanoparticles coated with polysorbate 80 increased resveratrol concentration in the brain; thus, it could be a promising nanomedical device and adjuvant therapy for NDDs such as PD. ${ }^{167}$

In the form of nanoformulation in a bind with polybutyl cyanoacrylate, curcumin shows neuroprotective effects in $\mathrm{PD}$, crosses the $\mathrm{BBB}$, and is thought to alleviate PD symptoms. ${ }^{130}$ In another study, piperine and curcumin co-encapsulated glyceryl monooleate (GMO) nanoparticles increased suppression of $\mathrm{S}$ protein oligomerization and fibril formation, decreased rotenone-induced toxicity, oxidative stress through reducing GSH depletion induced by rotenone, and apoptosis via reducing the ratio of Bcl-2 to Bax, and initiation of the autophagic pathway in vitro. Furthermore, in vivo research showed that such nanoparticles could cross the BBB, reverse rotenone-induced 
Table I Nanoformulations of Phytochemicals and Synthetic Drugs in Combating AD and PD

\begin{tabular}{|c|c|c|c|c|c|}
\hline Disease & Component & Nano Vehicle/Method & Study Type & Results & References \\
\hline \multirow[t]{18}{*}{ AD } & \multicolumn{5}{|c|}{ Phytochemicals Nanoformulations } \\
\hline & \multirow[t]{2}{*}{ Resveratrol } & SLNs; ASDs & $\begin{array}{l}\text { In vitro: endothelial cells; In vivo: } \\
\text { A /APP/PSI mouse }\end{array}$ & $\begin{array}{l}\downarrow \text { formation of } A \beta(1-42) \text { aggregates, } \downarrow q \text { quick clearance, } \downarrow A \beta \text { plaque density in the } \\
\text { cortex, caudoputamen, and hippocampus }\end{array}$ & {$[126,184]$} \\
\hline & & NLCs & $\begin{array}{l}\text { In vitro: fresh nasal mucosa of } \\
\text { sheep; In vivo: male Sprague-Dawley } \\
\text { rats }\end{array}$ & $\begin{array}{l}\uparrow \text { memory function, } \uparrow \text { permeation across nasal mucosa via decreasing the } \\
\text { crystallinity of particles through a lipid-oil mixture }\end{array}$ & [127] \\
\hline & \multirow[t]{9}{*}{ Curcumin } & PLGA; ASDs & In vitro/ in vivo: Tg2576 mice & $\begin{array}{l}\uparrow \text { working and recall memory via activating canonical Wnt/ } \beta \text {-catenin pathway, } \\
\uparrow \text { curcumin bioavailability, } \downarrow \text { rate of amyloid and plaque burden }\end{array}$ & {$[129,184]$} \\
\hline & & PLGA & $\begin{array}{l}\text { In vitro: SK-N-SH cells, a human } \\
\text { neuroblastoma cell line }\end{array}$ & $\uparrow$ curcumin stability & [131] \\
\hline & & \multirow[t]{3}{*}{ PLGA-PEG-B6 } & In vitro: HT22 cells & $\uparrow$ cellular absorption, $\uparrow$ blood compatibility & [134] \\
\hline & & & In vivo: APP/PSI mice & $\uparrow$ spatial learning and memory performance & [134] \\
\hline & & & Ex vivo & $\downarrow$ hippocampus-amyloid production and deposit, $\downarrow$ tau hyperphosphorylation & [134] \\
\hline & & PLGA & In vitro/in vivo: Wistar rats & $\uparrow N S C$ proliferation and neuronal differentiation in the hippocampus & [133] \\
\hline & & PLGA & In vivo: Wistar rats & $\begin{array}{l}\text { †hippocampus neurogenesis, cognition, and memory, } \uparrow \text { canonical Wnt/ } \beta \text {-catenin } \\
\text { pathway }\end{array}$ & [133] \\
\hline & & PLGA & In vitro: rat hippocampal cells & $\downarrow A \beta$ aggregates & [132] \\
\hline & & Nanoliposomes & $\begin{array}{l}\text { In vitro: } h A P P s w \text { SH-SY5Y cell; In } \\
\text { vivo: APP/PSI mice }\end{array}$ & $\downarrow A \beta$-induced toxicity, $\downarrow A \beta$ deposits & [135] \\
\hline & Naringenin & NEs & In vitro: SH-SY5Y cells & $\downarrow$ APP, $\downarrow$ BACE, $\downarrow$ tau phosphorylation & [136] \\
\hline & \multirow[t]{5}{*}{ Quercetin } & PLGA; ASDs & $\begin{array}{l}\text { In vitro: SH-SY5Y cells; In vivo: A } \beta / \\
\text { C. elegan CL2006 }\end{array}$ & $\begin{array}{l}\text { Neurotoxicity of the } \mathrm{Zn}^{2+}-\mathrm{A} \beta 42 \text { system, } \uparrow \text { neuron cell survival by suppressing } \mathrm{Zn}^{2} \\
{ }^{+}-\mathrm{AB} 42 \text { system, } \downarrow \text { aggregation of proteins }\end{array}$ & {$[140,184]$} \\
\hline & & PLGA-NPs & In vivo: APP/PSI mice & $\uparrow c o g n i t i v e$ functions and memory & [140] \\
\hline & & NPQ & In vivo: SAMP8 mice & $\uparrow o r a l$ absorption, $\uparrow$ bioavailability, $\uparrow$ cognitive and memory & [137] \\
\hline & & NPs & In vivo: male Albino Wistar rats & $\uparrow$ residence period in the systemic circulation, $\uparrow$ bioavailability & [139] \\
\hline & & $\begin{array}{l}\text { Cyclodextrin-dodecyl } \\
\text { carbonate nanoparticles }\end{array}$ & In vitro: SH-SY5Y cells & $\downarrow T L R 4$ and COX-2 signaling pathway, $\uparrow B B B$ penetration, $\uparrow$ bioavailability & [138] \\
\hline
\end{tabular}


Table I (Continued).

\begin{tabular}{|c|c|c|c|c|c|}
\hline Disease & Component & Nano Vehicle/Method & Study Type & Results & References \\
\hline & Rosmarinic acid & $\begin{array}{l}\text { CRMI97-ApoE-PAAM-CH- } \\
\text { PLGA }\end{array}$ & In vitro: SK-N-MC cells & $\downarrow$ degeneration of $A \beta$-insulted neurons, $\uparrow$ BBB transportation, $\downarrow$ caspase- 3 , and c-Jun & {$[14 \mid]$} \\
\hline & \multirow[t]{3}{*}{$\begin{array}{l}\text { Epigallocatechin } \\
\text { 3-gallate }\end{array}$} & Nanolipidic & $\begin{array}{l}\text { In vitro: murine neuroblastoma } \\
\text { cells; In vivo: male Sprague Dawley } \\
\text { rats }\end{array}$ & $\uparrow$ neuronal $\alpha$-secretase, $\uparrow$ oral bioavailability & [142] \\
\hline & & Nano & In vitro: SH-SY-5Y cell & $\downarrow$ cellular toxicity, $\left.\downarrow \mathrm{A}\right|^{3+}$-induced $\mathrm{A} \beta 42$ fibrillation, and neurotoxicity & [143] \\
\hline & & $\begin{array}{l}\text { Stabilized selenium } \\
\text { nanoparticles coated with } \\
\text { Tet-I peptide }\end{array}$ & In vitro: $\mathrm{PCI} 2$ cells & $\downarrow A \beta$ fibrillation, $A \beta$ fibrils into harmless aggregates efficiently & [144] \\
\hline & $\begin{array}{l}\text { Ginsenoside } \\
\text { Rg3 }\end{array}$ & PLGA & $\begin{array}{l}\text { In vitro: } \mathrm{C} 6 \text { rat glial cells and THP-I } \\
\text { human monocytic cells line }\end{array}$ & $\uparrow B B B$ permeability, $\downarrow$ formation of $A \beta$ plaques, and eventual neurodegeneration & {$[150]$} \\
\hline & Ferulic acid & SLN & $\begin{array}{l}\text { In vitro: human neuroblastoma cells } \\
\text { (LAN 5) }\end{array}$ & $\downarrow$ ROS compared cells & [185] \\
\hline & Berberine & MWCNTs & $\begin{array}{l}\text { In vitro: } \mathrm{SH}-\mathrm{SY} 5 Y \text { cells; In vivo: male } \\
\text { Wistar rats }\end{array}$ & $\uparrow$ memory function recovery, $\uparrow$ biochemical levels in brain tissue, and $\downarrow A \beta$ & [148] \\
\hline & Sesamol & SLN & In vivo: male Wistar rats & $\downarrow$ neuronal malfunction, $\downarrow$ memory impairments by reducing oxidative stress & [146] \\
\hline & Huperzine A & Lf-TMC NPs & $\begin{array}{l}\text { In vitro/ex vivo: } 16 \mathrm{HBE} \text { and SH- } \\
\text { SY5Y cell lines }\end{array}$ & $\uparrow$ mucoadhesion, $\uparrow$ widely dispersed in the brain over a long period & [149] \\
\hline & \multicolumn{5}{|c|}{ Nanoformulations of synthetic drugs } \\
\hline & Memantine & PEG-PLGA & $\begin{array}{l}\text { In vitro/in vivo: } A P P / P S I \text { and } C 57 B L / \\
6 \text { mice }\end{array}$ & $\downarrow A \beta$ plaques & [156] \\
\hline & Donepezil & Liposome & In vivo: male Wistar rats & $\uparrow$ brain bioavailability & [154] \\
\hline & \multirow[t]{2}{*}{ Rivastigmine } & Liposome & In vivo: male Wistar albino rats & $\uparrow$ memory recovery, $\downarrow$ metabolic abnormalities & [152] \\
\hline & & SLN & In vitro: Franz diffusion cell & $\uparrow$ diffusion and not affect nasociliary disruption or cell necrosis & [153] \\
\hline & Tarenflurbil & $\mathrm{NPs} / \mathrm{SLN}$ & In vitro: brain cells & $\uparrow$ brain biodistribution pattern, $\uparrow$ the pharmacokinetic behavior & [160] \\
\hline & Estradiol & PLGA & In vivo: male Sprague-Dawley & $\uparrow$ brain estradiol levels & [158] \\
\hline & $\begin{array}{l}\text { Galantamine } \\
\text { hydrobromide }\end{array}$ & SLN & $\begin{array}{l}\text { In vitro/ in vivo: male New Zealand } \\
\text { rabbits }\end{array}$ & $\uparrow$ substantial memory restoration potential, $\uparrow$ bioavailability & [155] \\
\hline
\end{tabular}




\begin{tabular}{|c|c|c|c|c|c|}
\hline & bFGF & STL-PEG-PLGA & In vivo: male Sprague-Dawley rats & $\begin{array}{l}\downarrow \text { neuronal degeneration, } \downarrow \text { learning impairments, } \uparrow \text { direct transport of bFGF into } \\
\text { the rat brain, } \downarrow \text { peripheral adverse reactions }\end{array}$ & [162] \\
\hline \multirow[t]{17}{*}{ PD } & \multicolumn{5}{|c|}{ Phytochemicals Nanoformulations } \\
\hline & \multirow[t]{4}{*}{ Resveratrol } & NPs & $\begin{array}{l}\text { In vitro/ in vivo: male albino Wistar } \\
\text { rats }\end{array}$ & $\begin{array}{l}\text { †resveratrol blood levels for a more extended period, } \uparrow \text { bioavailability, } \uparrow \\
\text { pharmacological impact }\end{array}$ & [164] \\
\hline & & Lips@Fe3O4 & $\begin{array}{l}\text { In vitro/ In vivo: male Sprague- } \\
\text { Dawley rats }\end{array}$ & $\begin{array}{l}\uparrow \text { sustained and delayed drug release, } \uparrow \text { efficiently penetrate the BBB, } \uparrow d r u g \\
\text { concentration at the targeted area in the presence of an external magnetic field }\end{array}$ & [165] \\
\hline & & $\begin{array}{l}\text { Vitamin E loaded resveratrol } \\
\text { NEs }\end{array}$ & In vitro: brain cells & 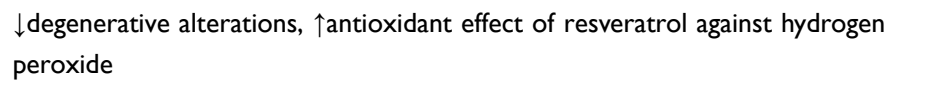 & [166] \\
\hline & & PS80-coated poly lactide NPs & Ex vivo: C57BL/6 mice & †resveratrol concentration in the brain & [167] \\
\hline & \multirow[t]{2}{*}{$\begin{array}{l}\text { Curcumin and } \\
\text { piperine }\end{array}$} & \multirow[t]{2}{*}{ GMO-NPs } & In vitro: rat $\mathrm{PCI} 2$ cell line & $\begin{array}{l}\downarrow \alpha S \text { protein oligomerization and fibril formation, } \downarrow \text { rotenone-induced toxicity, } \\
\downarrow \text { GSH depletion induced by rotenone, } \downarrow \text { ration of Bcl-2/Bax, } \uparrow \text { autophagic pathway }\end{array}$ & [168] \\
\hline & & & $\begin{array}{l}\text { In vivo: male Balb/c mice and male } \\
\text { C57BL/6 mice }\end{array}$ & $\begin{array}{l}\uparrow c r o s s \text { the BBB, } \downarrow \text { rotenone-induced motor coordination impairment, } \\
\downarrow \text { dopaminergic neuronal degeneration }\end{array}$ & [168] \\
\hline & Naringenin & Vitamin E loaded NEs & In vitro/in vivo: Wistar rats & $\begin{array}{l}\uparrow \text { muscular coordination, grip strength, } \uparrow \text { swimming activity, } \uparrow \text { naringenin in the } \\
\text { brain, } \uparrow \text { bioavailability, } \uparrow G S H, \uparrow S O D, \downarrow M D A\end{array}$ & [169] \\
\hline & Gallic acid & PEI-HAS-NPs & In vitro: $\mathrm{PC}-12$ cells & $\downarrow \alpha S N$ aggregating, \hazardous oligomers. & [186] \\
\hline & \multicolumn{5}{|c|}{ Nanoformulations of Synthetic Drugs } \\
\hline & Levodopa & NPs & In vitro/ in vivo & $\downarrow$ dyskinesia & [172] \\
\hline & \multirow[t]{2}{*}{ Bromocriptine } & $\begin{array}{l}\text { SLN based on a tristearin/ } \\
\text { tricaprin }\end{array}$ & In vitro & $\begin{array}{l}\text { Controlled drug release by surrounding solid lipid barrier, firmly contained during } \\
\text { the extended time established }\end{array}$ & [174] \\
\hline & & Chitosan & In vivo: Swiss albino mice & $\uparrow$ absorption in the brain and protects catalepsy and akinesia & [17I] \\
\hline & \multirow[t]{2}{*}{ Ropinirole } & PLGA & In vitro/ in vivo: male Wistar rats & $\downarrow$ neurodegeneration & [175] \\
\hline & & PLN & In vitro/in vivo: male albino mice & $\downarrow$ dose and dosing frequency, optimizing the therapeutic index, $\downarrow$ side effects & [177] \\
\hline & \multirow[t]{2}{*}{ Selegiline } & NEs & $\begin{array}{l}\text { In vitro: neuro-2a neuroblastoma } \\
\text { cell line }\end{array}$ & $\begin{array}{l}\uparrow G S H, \uparrow S O D, \downarrow T B A R S \uparrow \text { drug bioavailability, } \uparrow \text { brain uptake, } \downarrow \text { decreased dopamine } \\
\text { depletion }\end{array}$ & {$[18 \mid]$} \\
\hline & & NEs & In vivo: Wistar rats & $\downarrow$ neurodamage caused by free radicals, $\downarrow$ subsequent metabolic alterations & [182] \\
\hline
\end{tabular}




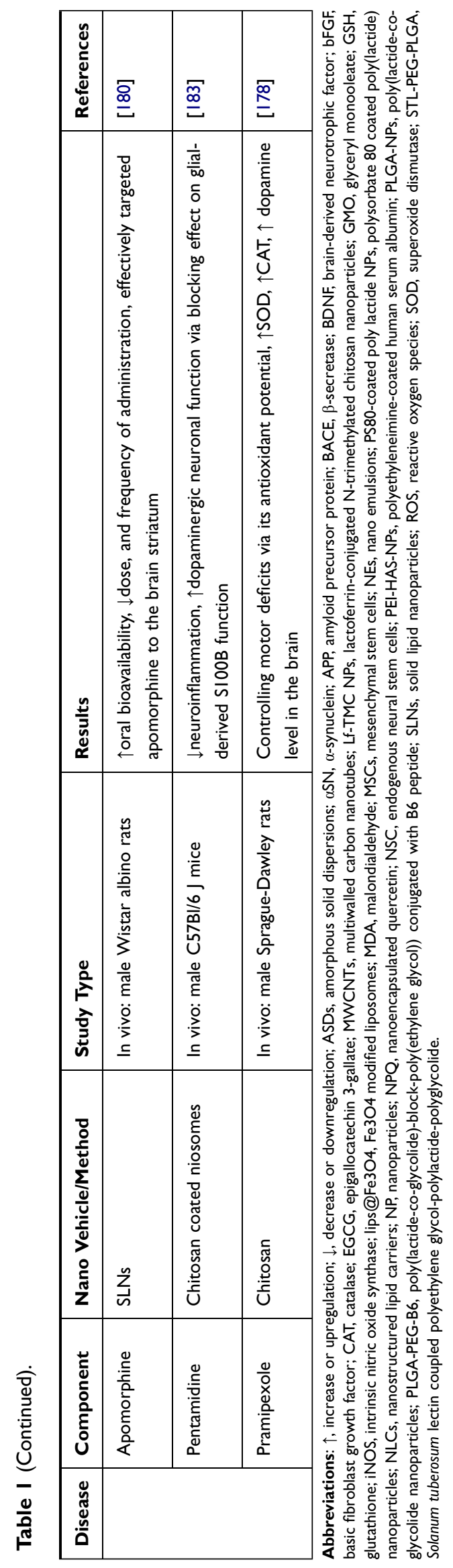

motor coordination impairment, and prevent dopaminergic neuronal degeneration in a PD mouse model. ${ }^{168}$

Gaba et al found that combining vitamin E-loaded naringenin (another flavonoid) nanoemulsion with conventional medication (levodopa) effectively restored the consequences of 6-hydroxydopamine (6-OHDA), namely improved muscular coordination, grip strength, and swimming activity. It also increased the naringenin level in the brain and boosted brain bioavailability in a rat model. Although GSH and SOD levels were considerably greater, malondialdehyde (MDA) showed a significant decrease in the group treated with naringenin nanoemulsion intranasally coupled with levodopa. ${ }^{169}$

Quercetin, a bioflavonoid present in a variety of fruits and vegetable, has well-known neuroprotective through repairing mitochondrial electron transport chain abnormalities and upregulated, increasing mitochondrial quality control $^{170}$ and anti-inflammatory properties. Furthermore, quercetin has a high capacity to remove ROS. Considering its favorable benefits, low solubility and bioavailability have limited its therapeutic uses; so, the bioavailability and effectiveness of quercetin nanocrystals were higher in PD-like animals than in the naïve quercetin. There was a substantial increase in antioxidant enzyme functions and total GSH levels in the hippocampus region and a decrease in malondialdehyde levels. ${ }^{1}$

Therefore, the nanoformulations of resveratrol, curcumin, piperine, naringenin, quercetin, and gallic acid have shown various therapeutic effects on PD by improving bioavailability and reducing the harmful effects of rotenone. From the mechanistic point, nanophytochemicals increase neurogenesis, suppress apoptotic pathways, and decrease oxidative stress/inflammation. Table 1 shows the pre-clinical evidence on using nanoformulations of phytochemicals against AD.

\section{Parkinson's Disease and Nanoformulation of Synthetic Drugs}

Several synthetic drugs are being indicated for PD symptoms; however, the lack of efficacy urges the need to find a way to counter their possible pharmacokinetic limitations. Levodopa (a dopamine precursor) is the most therapeutically beneficial medication in PD treatment. However, the clinical response is unpredictable and inaccurate because of its inconsistent oral absorption and variations in plasma concentrations. Variations in motor function and the emergence of drug-induced involuntary movements provide difficulty in treating $\mathrm{PD} .{ }^{171}$ In rats, levodopa 
administration can result in dyskinesia. Meanwhile, in dyskinetic rats, the treatment of levodopa methyl ester/ benserazide-loaded nanoparticles decreased dyskinesia while avoiding the rise of molecules strongly linked with the development of dyskinesia. ${ }^{172}$

Like another drug, bromocriptine is an ergot with dopamine receptor agonist activity that has been commonly used in practice trials to postpone and reduce the destructive motor fluctuations coupled with prolonged levodopa treatment in PD. Bromocriptine protects dopaminergic cells, directly and indirectly, to act as a dopamine receptor agonist. ${ }^{173}$ The promising results implied that SLN based on a tristearin/tricaprin combination might be suggested as a novel method for administering bromocriptine during PD treatment to provide controlled drug release by the surrounding solid lipid barrier and firmly contained during long time established. Furthermore, this method may offer a unique technique for achieving stable medication levels, enhancing patient adherence to therapy, and decreasing long-term adverse effects. ${ }^{174}$ Also, intranasal treatment of bromocriptine-loaded chitosan nanoparticles improved bromocriptine absorption in the brain and protected catalepsy and akinesia in a mouse model of PD. ${ }^{171}$

A novel drug delivery system comprised PLGA nanoparticles filled with ropinirole was created for PD treatment. In the animal model tested, this approach could reverse PD-like symptoms. ${ }^{175}$ Ropinirole is a nonergoline dopamine receptor agonist that attaches to D2-receptors in the striatum and substantia nigra with specificity similar to dopamine. Its antiparkinsonian effect is elicited via increasing striatal neuronal firing rates through the selective activation of D2-dopamine receptors. ${ }^{176}$ The carrier technology might provide an exciting way of CNS neurotherapeutic administration. Polymer-lipid hybrid nanoparticles might be regarded as a strong, safe, and stable alternative to traditional dose formulations, which would aid in reducing the dose and dosing frequency, optimizing the therapeutic index, ensuring proper, eliminating peakto-valley fluctuations, and lowering the risk of side reactions. ${ }^{177}$ As another non-ergot-based dopamine agonist, pramipexole is particularly useful when combined with levodopa or monoamine oxidase-B inhibitors to slow the progression of PD. It has been revealed that intranasal chitosan nanoparticles of pramipexole outperformed oral or solution dosage forms in controlling motor deficits in a rotenone PD model via its antioxidant potential in increased SOD and CAT function while enhanced dopamine level in the brain significantly. ${ }^{178}$
Oral administration is a method of delivery that may be used in a variety of therapeutic conditions. Unfortunately, oral administration of apomorphine (a dopamine receptor agonist) was ineffective due to fast degradation in the gastrointestinal tract and the first-pass effect, culminating in bioavailability of $1.7 \%{ }^{179}$ Apomorphine oral bioavailability improved via utilizing SLNs as carriers. The drug's dose and frequency of administration can be decreased. The in vivo drug distribution data showed that SLNs effectively focused apomorphine to the brain striatum, one of the most damaged areas, substantially improving apomorphine's capacity to treat PD. ${ }^{180}$ Compared to the free medication, selegiline (a monoamine oxidase inhibitor) encapsulated in nanoemulsions demonstrated greater antioxidant activity via increasing GSH and SOD while reducing the level of thiobarbituric acid reactive substances (TBARS). Additionally, compared to a control group, a haloperidol-induced rat model of PD treated with the selegiline nanoemulsions exhibited increased drug bioavailability and brain uptake, resulting in decreased dopamine depletion. ${ }^{181}$ The findings suggested that the proposed formulation might be a promising strategy for effective intranasal administration of selegiline into the CNS, reducing neurodamage caused by free radicals and preventing subsequent metabolic alterations during PD. ${ }^{182}$

Pentamidine is among the most potent inhibitors of S100B activity, a crucial component in neuroinflammation that underpins the pathophysiology of $\mathrm{PD}$, although its ability to penetrate the $\mathrm{BBB}$ is restricted. To deal with this issue, researchers utilized chitosan-coated niosomes with entrapped pentamidine to restore dopaminergic neuronal function via its suppressing effect on glial-derived S100B function, which resulted in a significant enhancement in parkinsonian motor dysfunctions. ${ }^{183}$ Overall, the nanoformulation of synthetic drugs such as levodopa, bromocriptine, ropinirole, selegiline, apomorphine, pentamidine, and pramipexole have presented various protective roles on PD by reducing dyskinesia, lessening the side effects of naive drugs, improving the bioavailability of drugs, suppressing glial-function/oxidative stress, and enhancing dopamine level in the brain.

Table 1 shows the pre-clinical evidence on using nanoformulations of phytochemicals and synthetic drugs against $\mathrm{AD}$ and $\mathrm{PD}$.

\section{Amyotrophic Lateral Sclerosis and Nanoformulations}

ALS, commonly known as motor neuron disease or Lou Gehrig's disease, is a fast-progressing NDDs that causes 
muscular movement neurons to fail. ALS explicitly targets motor neurons in the brain, brainstem, and spinal cord, resulting in progressive motor neuron degeneration and muscular atrophy, leading to paralysis and death because of respiratory failure. Gene mutations that affect regular protein activity oxidative stress, protein misfolding and aggregation, and mitochondrial malfunction neuroinflammation are implicated in the causes of ALS. ${ }^{22}$

\section{Amyotrophic Lateral Sclerosis and Phytochemicals Nanoformulations}

In 2018, Ahmadi et al designed and conducted a randomized clinical trial to investigate the efficacy and safety of oral capsules containing $80 \mathrm{mg}$ nanomicelles curcuminoids combined with riluzole in patients with ALS. Results emphasized that nanocurcumin was safe with no serious adverse events, which increased the probability of survival in treated patients, especially those with irritable bladder. ${ }^{23}$

According to some findings, pathological inclusions, including SOD1 in ALS, are comparable to amyloid fibrils produced in vitro. Fibrillar inclusions characterize the pathology of neural tissues in mouse models that express human SOD1 mutations. ${ }^{187}$ Inhibiting SOD1 amyloid development could be a helpful approach for combating ALS. Accordingly, curcumin prevented SOD1 fibrillation and promoted the formation of smaller, disordered aggregates. Curcumin nanoparticles with a more excellent water solubility showed similar aggregation management as curcumin bulk. ${ }^{188}$

Furthermore, Tripodo et al introduced a new drug delivery system to treat NDDs, especially ALS. A carried-in-carrier system was produced via loading the curcumin and mesenchymal stromal cells in the curcuminloaded micelles. According to the research, these nanoparticles achieved maximal loading in micelle-loaded mesenchymal stromal cells in a matter of minutes, and the loading was concentration-dependent. When naked curcumin was utilized, mesenchymal stromal cells showed apparent cytotoxicity; however, naive curcumin micelles shielded them from this impact. ${ }^{189}$

\section{Amyotrophic Lateral Sclerosis and Nanoformulations of Synthetic Drugs}

The FDA has authorized only two drugs to manage ALS, riluzole and edaravone supporting neurons by removing ROS from the nervous system. ${ }^{190}$ Riluzole is one of only two approved drugs to treat ALS. Furthermore, because riluzole is a $\mathrm{P}$-glycoprotein (P-gp) substrate, its brain distribution is hampered by efflux transporters at the BBB.
Verapamil cocktail liposomes reduced p-gp levels. TNF- $\alpha$ or $\mathrm{H} 2 \mathrm{O} 2$-induced increases in drug efflux transporters. Thus, a liposomal co-delivery method that may efficiently transport riluzole to brain cells by decreasing efflux pumps with verapamil, a P-gp inhibitor, could circumvent riluzole pharmacoresistance for enhancing ALS therapy. ${ }^{191}$ SLNs containing riluzole had higher drug loading and effectiveness than free riluzole and could transport more into the brain with less indiscriminate biodistribution in rats. ${ }^{192}$

Besides, dimethyl fumarate is effective in the treatment of recurrent ALS. On the other hand, such pills cause flushing, gastrointestinal problems, and more significant side effects. As intranasal transport vehicles, simple tristearin SLN, coated with polysorbate 80 and cationized with dimethyldioctadecylammonium chloride, were evaluated. An in vitro investigation using a mouse brain microvascular endothelial cells model revealed that cationic SLN had greater brain penetration. The biodistribution of polysorbate 80 -treated SLN in mice was investigated using fluorescence imaging following intraperitoneal or intranasal administration. Thus, polysorbate 80-treated SLN entered the brain via intraperitoneal and intranasal routes; however, they were primarily collected in the liver and spleen via the intraperitoneal way. ${ }^{193}$

Neurodegeneration in ALS mice is linked to the proliferative repair efforts of ependymal stem progenitor cells, typically dormant in the spinal cord. As a result, controlling the development of ependymal stem progenitor cells might be a viable approach for preventing neurodegeneration. A mutant version of the human SOD1 gene is overexpressed in the G93A-SOD1 transgenic mouse model of ALS. In addition, FM19G11, a hypoxia-inducible factor (HIF) modulator loaded in the gold nanoparticles, activates the PI3K/Akt and mitochondrial uncoupling protein (UCP2) signal transduction pathways, which regulate stemness, self-renewal, and proliferation is responsible for this action. This research might pave the way for novel methods to slow the neurodegeneration and disease progression in ALS patients based on FM19G11loaded. $^{194}$

Therefore, curcumin nanomicelle has protective effects on ALS by regulating different dysregulated pathways like SOD1 fibrillation. Additionally, nanomicelles improve the bioavailability of curcumin and lower the cytotoxicity responses. Nanoformulations of synthetic drugs like riluzole, edaravone, dimethyl fumarate, verapamil, and FM19G11 improve their bioavailability and control the development of ependymal stem progenitor cells by 
activating the PI3K/Akt and UCP2 signal transduction pathways.

\section{Stroke and Nanoformulation}

Cerebrovascular diseases are the primary cause of physical impairment, the second most significant cause of death, and the main reason for hospital inpatient hospitalization for many patients. Stroke is the most frequent cerebrovascular illness and is the third-largest cause of mortality in the developed world, causing 15 million injuries and 5 million fatalities each year. Ischemic stroke accounts for $80 \%$ of all stroke injuries caused by hypoperfusion, thrombosis, or embolism. ${ }^{29}$ Several variables, particularly oxidative stress, apoptosis, edema caused by ionic imbalance, and inflammation, are thought to have a role in the pathophysiology of ischemic stroke. ${ }^{195}$ Clinical trials have demonstrated that the biological activities of several herbal formulations produced from natural products are related to their antioxidant properties, which is considered as one of the treatment mechanisms of ischemic stroke. The main issue with using phytochemicals in stroke treatment is their poor bioavailability, limiting their efficacy in clinical studies. $^{24}$

\section{Stroke and Phytochemicals Nanoformulations}

In rats with transient middle cerebral artery occlusion, the intraarterial injection of resveratrol nanoparticles exhibited additional safety from cerebral ischemia/reperfusion (I/R) damage. Resveratrol nanoparticles reduced oxidative stress caused by ischemia-reperfusion via decreasing MDA, avoided brain edema, rescued neurons from apoptosis through decreasing Bax and cleaved caspase-3, and promoted neurogenesis by increasing brain-derived neurotrophic factor (BDNF) expression. ${ }^{196}$

Curcumin therapy has vascular protective benefits in people at risk of stroke. Curcumin incorporated in a solid lipid matrix of SLNs resists enzymatic breakdown during absorption and has a long circulation duration and lower elimination in vivo after absorption. After curcumin-SLNs treatment, SOD, CAT, GSH, and mitochondrial complex enzyme activity enhanced, but lipid peroxidation, nitrite, and acetylcholinesterase rates declined. ${ }^{197}$ In another study, oral therapy with nanoencapsulated quercetin could defend from oxidative damage by decreasing the expression of iNOS and caspase- 3 activities and reducing the loss of pyramidal neurons from the hippocampus CA1 and CA3 subfields in young and old rats subjected to $\mathrm{I} / \mathrm{R}$. Early therapy with nanodrugs improves survival chances due to less neuronal loss. ${ }^{198}$ Following cerebral I/R, deliverable quercetin-loaded polymeric nanocapsules showed increased brain uptake and impressive mitochondrial localization. In both young and old rats, this novel regulated mitochondrial delivery of quercetin alleviated histopathological intensity by protecting mitochondrial structural and functional integrity via sequestering ROS through increasing GSH level and SOD and CAT activities regulating mitochondrial ROS-driven apoptotic cell death. ${ }^{199}$

The primary active component of Panax notoginseng is Panax notoginsenoside. When administered orally, the unique Panax notoginsenoside-loaded core-shell hybrid liposomal vesicle (HLV) delivery method improved free drug bioactivity. Furthermore, decreased brain water content and infarction volume detecting cerebral ischemia/ reperfusion in the acute myocardial ischemia group compared to the control group, lactate dehydrogenase (LDH) in the serum, $\mathrm{H} 2 \mathrm{O} 2$, and MDA increased significantly, whereas SOD decreased significantly. Compared to the model group, there were substantial restorations of the enzymatic level in the Panax notoginsenoside-treated group, particularly in the Panax notoginsenoside-HLVtreated group the improved physicochemical characteristics. $^{200}$

With stem cell treatment, the potential of overcoming the damage caused by cerebral ischemia appeared promising. The entrapped drug naringenin has a prolonged release pattern in a nanoformulation of naringenin. The findings suggest that naringenin-loaded gelatin-coated polycaprolactone nanoparticles have protective effects on human mesenchymal stem cells via reducing the inflammatory responses (TNF- $\alpha$, IL- $1 \beta, \mathrm{COX}-2$, and iNOS) through NF- $\kappa \mathrm{B}$ pathways caused by oxygen-glucose deprivation. ${ }^{201}$

As another phytochemical, retinoic acid nanoparticles decreased microglial activation in N9 microglial cells; organotypic hippocampus slices culture and effectively inhibited LPS-induced release of nitric oxide (NO) and the expression of iNOS and promoted arginase-1 and IL4 production. ${ }^{25}$

In summary, nanoformulations of resveratrol, curcumin, quercetin, ginsenoside, naringenin, and retinoic acid have various effects on stroke. Such therapeutic responses are applied by reducing oxidative stress by enhancing the activation of SOD, CAT, GSH, and mitochondrial complex enzymes. Nanophytochemicals also decrease Bax and cleaved caspase-3, increase BDNF expression, and reduce the loss of pyramidal neurons from the hippocampus CA1 
and CA3. Nanophytocompounds also reduce the inflammatory mediators (eg, TNF- $\alpha$, IL-1 $\beta$, COX-2, and iNOS) through NF- $\kappa \mathrm{B}$ pathways, inhibiting LPS-induced nitric oxide (NO) promoted arginase-1 and IL-4 production.

\section{Stroke and Nanoformulations of Synthetic Drugs}

The findings revealed that recombinant tissue plasminogen activator (rtPA) to PEG-PCL nanoparticles equal 10\% of a normal rtPA dosage in dissolving fibrin clots. Such nanoparticles had a neuroprotective effect after localized cerebral ischemia, as seen by reduced infarct volume and improved neurological impairment. Such conjugation showed a half-life of about 18 times greater than free rtPA. $^{202}$ Medication with liposomal fasudil before tPA may reduce the chance of tPA-derived cerebral hemorrhage and lengthen the therapeutic time window of thrombolytic therapy. The combined treatment may be a helpful therapeutic alternative for ischemic stroke. ${ }^{203}$ The antioxidant capabilities of $\mathrm{CeO}$ nanoparticles aided cell viability and dramatically decreased free radical generation. $\mathrm{CeO}$ nanoparticles substantially reduced cell death in an animal model of stroke. Besides, Pt nanoparticles have been used as ROS scavengers in vitro and in vivo in mice, reducing the oxidative stress caused by ischemia. Similarly, Pt nanoparticles enhanced motor function and reduced infarct volume in the brain. ${ }^{26}$

Single-walled carbon nanotubes showed an antiinflammatory impact in a rat stroke model and prevented neurons from ischemia injury. ${ }^{204}$ Local administration of SOD-loaded nanoparticles produced persistent protective implications resulting in a $65 \%$ decrease in infarct volume, whereas SOD solution therapy increased infarct volume by $25 \%$. The prolonged lifespan of rats treated with nanoparticles indicated the superior protective impact of SODloaded nanoparticles. An angiogenic growth factor, vascular endothelial growth factor (VEGF), stimulated neurogenesis and cerebral angiogenesis, which reduced ischemic brain damage. VEGF-encoding plasmids were encased in liposomes functionalized with transferrin for intravenous administration, allowing them to cross the BBB. $^{29}$

In another study, VEGF and angiopoietin-1 (Ang1) are two essential factors triggering angiogenesis. ${ }^{205}$ Despite VEGF and Ang1's potential therapeutic potential, their in vivo short half-life through direct delivery made some limitations. ${ }^{206}$ Additional studies suggested that the hyaluronic acid-based biodegradable hydrogel scaffold, mixed with PLGA hydrogel, is a potential material capable of inducing angiogenesis in the ischemic area by releasing VEGF and Ang1, providing a favorable niche for neural repair in the later stages of stroke. In addition, such nanoformulation stimulated vascularization and axonal development. ${ }^{207}$ After brain ischemia, Zhao et al utilized a transferrin-coupled liposomes vector to supply VEGF to rats. They discovered that a single intravenous injection of the vector induced brain-specific VEGF production, improved neuroprotection, and stimulated neovascularization. ${ }^{208}$

In all, the nanoformulations of rtPA, fasudil, VEGF, Ang-1, and VEGF modulate stroke symptoms by reducing infarct volume and neurological impairment, increasing angiogenesis in the ischemic area, elevating vascularization and axonal development and increasing neuroprotection via reducing cerebral infarcts/neovascularization.

Table 2 shows the pre-clinical evidence on the use of phytochemical/synthetic nanoparticles against ALS and stroke.

\section{Other NDDs and Nanoformulation}

Nanoformulations have also shown potential to combat other NDDs, including HD and MS. HD is a neurological condition that is inherited in an autosomal dominant manner. HD begins in middle age and progresses to death 15-20 years later, with the following signs and symptoms, including uncontrollable movement problems, cognitive deficits, and mental aspects. This disease is defined by an irregular repeat of the Huntingtin gene's triplet cytosine-adenineguanine (CAG), which is translated at the protein level by a polyglutamine increase at the NH2-terminus of the protein huntingtin (HTT). ${ }^{209}$ The precise etiology of neuronal death in HD is unknown. However, the main drivers are glutamate excitotoxicity, mitochondrial malfunction, poor protein degradation, protein misfolding, caspase activation, transcriptional pathway dysregulation, decreased proteasome activity, and proteolysis abnormalities. ${ }^{210}$

Curcumin SLNs were administered to rats treated with 3-nitropropionic-acid (3-NP). This toxin induces HD-like neuropathology in rodents, leading to a decline in HD-like neurodegeneration and a considerable increase in mitochondrial complex function and cytochrome rates. The results demonstrated that the enhanced bioavailability of curcumin by SLN encapsulation has a distinct advantage over curcumin alone. Curcumin-SLNs indeed recovered GSH levels and SOD activity. Compared to 3-NP-treated rats, curcumin-SLN-treated rats demonstrated a significant difference in neuromotor coordination. ${ }^{211}$ In a recent report, curcumin-loaded nanoparticles based on 
Table 2 Phytochemical/Synthetic Nanoformulations Against ALS and Stroke

\begin{tabular}{|c|c|c|c|c|c|}
\hline Disease & Component & $\begin{array}{l}\text { Nano Vehicle/ } \\
\text { Method }\end{array}$ & Study Types & Results & References \\
\hline \multirow[t]{7}{*}{ ALS } & \multicolumn{5}{|c|}{ Phytochemicals Nanoformulations } \\
\hline & \multirow[t]{3}{*}{ Curcumin } & NPs & In vitro: MSCs & Without cytotoxicity & [189] \\
\hline & & NPs & In vitro: human monocytic THP-I cell & $\downarrow$ SODI, $\uparrow$ water solubility & [188] \\
\hline & & Nanomicelles & Clinical trial & $\uparrow$ safety, $\downarrow$ serious adverse effects & [23] \\
\hline & \multicolumn{5}{|c|}{ Nanoformulations of Synthetics Drugs } \\
\hline & FMI9GII & Gold & In vitro: epSPCs & $\uparrow$ self-renewal, $\uparrow P 13 K / A k t$ and UCP2 and proliferation of epSPCs & [194] \\
\hline & Riluzole & Liposome & $\begin{array}{l}\text { In vitro: mouse brain endothelial bEND.3 and } \\
\text { astrocyte C } 8 \text { DIA cells }\end{array}$ & 个uptake of riluzole in BBB cell model, $\uparrow$ TNF- $\alpha$ or $\mathrm{H} 2 \mathrm{O} 2$ & [191] \\
\hline \multirow[t]{13}{*}{ Stroke } & \multicolumn{5}{|c|}{ Phytochemicals Nanoformulations } \\
\hline & Resveratrol & NPs & In vivo: male Sprague-Dawley rats & $\downarrow$ oxidative stress, $\downarrow$ MDA, $\downarrow$ brain edema, $\downarrow$ apoptosis, $\downarrow$ Bax and caspase-3, $\uparrow$ neurogenesis, $\uparrow$ BDNF expression. & [196] \\
\hline & Curcumin & SLNs & In vivo: male Wistar rats & $\begin{array}{l}\uparrow c \text { circulation duration, } \uparrow \mathrm{SOD}, \uparrow \mathrm{CAT}, \uparrow \mathrm{GSH}, \uparrow \text { mitochondrial complex enzyme activity, } \downarrow \text { lipid peroxidation, } \downarrow \text { nitrite, } \downarrow \\
\text { acetylcholinesterase }\end{array}$ & [197] \\
\hline & \multirow[t]{2}{*}{ Quercetin } & Nanoencapsulated & In vivo: male Sprague Dawley rats & $\downarrow$ iNOS, $\downarrow$ caspase- $3, \downarrow$ loss of pyramidal neurons & [198] \\
\hline & & Polymeric nanocapsules & In vivo: male Wistar rats & $\begin{array}{l}\uparrow \text { brain uptake, impressive mitochondrial localization, protecting mitochondrial structural and functional integrity } \\
\text { via sequestering ROS, } \uparrow G S H \text { level, SOD and CAT activities }\end{array}$ & [199] \\
\hline & Panax notoginsenoside & HLV & In vivo: male Sprague Dawley rats & $\uparrow$ bioactivity, $\downarrow$ brain water content, $\downarrow$ infarction volume, $\uparrow \mathrm{SOD}, \downarrow \mathrm{LDH}, \mathrm{H} 2 \mathrm{O} 2, \mathrm{MDA}$ & [200] \\
\hline & Naringenin & Gel-c-PCL & In vitro: MSCs & $\uparrow$ release pattern, $\downarrow$ TNF- $\alpha$, IL-I $\beta$, COX2 and iNOS) via $\downarrow N F-k B$ & [201] \\
\hline & Retinoic Acid & NPs & $\begin{array}{l}\text { In vitro: Murine N9 microglia; Organotypic } \\
\text { hippocampal slices culture }\end{array}$ & $\downarrow$ microglia activation, $\downarrow$ NO and the expression of iNOS, promoted arginase-I and IL-4 & [25] \\
\hline & \multicolumn{5}{|c|}{ Nanoformulations of Synthetic Drugs } \\
\hline & rtPA & PEG-PCL & In vivo: Sprague Dawley rats & $\downarrow$ infarct volume, $\downarrow$ neurological impairment, $\uparrow$ half-life that is about 18 time greater than free rtPA & [202] \\
\hline & Fasudil & Liposomal & In vivo: male Sprague-Dawley rats & $\downarrow$ tPA-derived cerebral hemorrhage, $\uparrow$ TTW of thrombolytic therapy with tPA & [203] \\
\hline & VEGF and Ang-I & HA-PLGA & $\begin{array}{l}\text { In vitro: HUAECs/primary NSCs; in vivo: } \\
\text { C57BL/6] rats }\end{array}$ & $\uparrow$ angiogenesis in the ischemic area, $\uparrow$ vascularization and axonal development. & [207] \\
\hline & VEGF & Tf-PLs & In vivo: male Sprague-Dawley rats & $\uparrow$ brain-specific VEGF production, $\uparrow$ neuroprotection via reducing cerebral infarcts, $\uparrow$ neovascularization & [208] \\
\hline
\end{tabular}

Abbreviations: $\uparrow$, increase or upregulation; $\downarrow$, decrease or downregulation; Akt, protein kinase B; BDNF, brain-derived neurotrophic factor; bFGF, basic fibroblast growth factor; CAT, catalase; COX2, cyclooxygenase-2; GSH glutathione; $\mathrm{H} 2 \mathrm{O} 2$, hydrogen peroxide; HA-PLGA, hyaluronic acid poly(lactic-co-glycolic acid); HLV, hybrid liposomal vesicle; gel-c-PCL NPs, gelatin-coated polycaprolactone nanoparticles; IL-I I , Interleukin; iNOS, nitric oxide synthase; INVITE MC, curcumin loaded micelles; LDH, lactate dehydrogenase; MDA, Malondialdehyde; MSCs, mesenchymal stem cells; NEs, nano emulsions; PS80-coated poly lactide NPs, polysorbate 80 coated poly(lactide) nanoparticles; NF-k 3 , INVITE MC, curcumin loaded micelles; LDH, lactate dehydrogenase; MDA, Malondialdehyde; MSCs, mesenchymal stem cells; NEs, nano emulsions; PS80-coated poly lactide NPs, polysorbate 80 coated poly(lactide) nanoparticles; NF-kß,
nuclear factor-kß; NLCs, nanostructured lipid carriers; NO, nitric oxide; NP, nanoparticles; NSC, endogenous neural stem cells; PI3K, phosphatidylinositol 3-kinase; SLNs, solid lipid nanoparticles; ROS, reactive oxygen species; SOD, superoxide dismutase; Tf-PLs, transferrin-coupled liposomes; TNF- $\alpha$, Tumor necrosis factor; tPA, tissue-type plasminogen activator; VEGF, vascular endothelial growth factor; UCP2, mitochondrial uncoupling protein. 
amphiphilic hyaluronan-conjugate showed neuroprotective properties, in an in vitro model of HD. ${ }^{212}$

In another study, treatment with rosmarinic acid-loaded SLNs significantly reduces impairments in body weight, beam walk, locomotor and motor coordination, as well as 3-NP-induced striatal oxidative stress via restored endogenous antioxidants enzyme (CAT and GSH). The importance of choosing the nasal route over the i.v. route is demonstrated by the optimal brain medication concentration. $^{213}$

MS is a chronic immune-mediated demyelinating condition of the CNS that can be relapsing-remitting or progressive, with axon loss and paralysis as a result. MS generally develops in adults between the ages of 20 and 50 , and women are more prone to developing MS. MS is characterized by a wide range of persistent physical, neurological, and psychotic disorders, including muscular weakness, weak reflexes, muscle spasms, trouble moving, poor coordination, and imbalance. Nanotechnology is a promising method that has made significant contributions to diagnosing and treating CNS-related diseases like MS. $^{214}$ Like another drug, dimethyl fumarate is a potential medication for treating MS; however, it is linked with repeated dosage, inadequate brain penetration, and gastrointestinal flushing. Studies demonstrated the superiority of nanocarriers carrying dimethyl fumarate in a once-daily dosing regimen vs thrice-daily plain dimethyl fumarate administration on critical metrics such as motor coordination, grip strength, weight, and locomotor activity. ${ }^{215}$ The same study showed that SLN-dimethyl fumarate improves bioavailability, biological residence, and brain absorption, implying that lipid nanocarrier formulations might help treat MS adequately. ${ }^{216}$ Also, an in vitro investigation of fluorescent SLN penetration using a mouse brain microvascular endothelial cell model revealed that cationic SLN had greater permeability values than SLN treated with polysorbate 80 . The in vivo images showed that polysorbate 80 -treated SLN could reach the brain, although they mostly collected in the liver and spleen. ${ }^{217}$

For example, exosomes, or tiny nanovesicles formed by dendritic cells, contain proteins and RNAs that help repair myelin sheaths. Exosomes have been proposed as a replacement for liposomes in administering medicinal drugs. Exosomes do not have toxicity effects and can quickly cross the $\mathrm{BBB}$, giving them great therapeutic benefits. By encouraging preoligodendrocytes to differentiate into myelin-producing cells, dendritic-derived exosomes significantly increased myelination and enhanced remyelination after damage. Moreover, serum exosomes nasally given to naive rats enhanced myelin content, oligodendrocyte precursor cell, and neural stem cell levels and reduced oxidative damage in hippocampal slice cultures. PLGA nanoparticles covalently crosslinked to myelin peptides reduced inflammation and modulated effector $\mathrm{T}$ cell function. $\mathrm{CeO}$ nanoparticles became stable with citrate/EDTA and acted as antioxidant in CNS ROS levels in C57/B16 MOG EAE mice after IV treatment. This therapy reduced clinical symptoms and motor deficits while reducing CNS damage caused by free radical buildup. ${ }^{214}$ In another study, artificial neurotrophins are highlighted as promising agents against neurodegeneration. ${ }^{218}$ The potential uses of phytochemical/synthetic nanoformulations against multiple NDDs are provided in Figure 3.

So, nanoformulations of phytochemicals and synthetic drugs critically modulated dysregulated mediators in NDDs, thereby combat neurodegeneration.

Table 3 shows the pre-clinical evidence on the use of phytochemical/synthetic nanoparticles against HD and MS.

\section{Conclusion and Future Outlook}

NDDs are defined as the progressive loss of neuronal architecture or activity, which is usually followed by neuronal death. The most prevalent neurodegenerative conditions are AD, PD, ALS, stroke, HD, and MS. Several dysregulated pathways are involved in the pathogenesis of NDDs, including neuronal oxidative stress, neuroapoptosis, and neuroinflammation (Figure 4). Such complex pathophysiological mechanisms and the pharmacokinetics limitations, lower efficacy, and higher side effects of conventional therapies urge the need to investigate alternative formulations and novel treatments. In recent decades, phytochemicals have been highlighted as a hopeful therapeutic agent in the prevention and treatment of cancer. Despite the effectiveness of plant secondary metabolites, they often suffer from poor bioavailability, low solubility, instability, decreased absorption, and low selectivity, which limit their therapeutic applications in cancer. Besides, rapid metabolism, chemical degradation, and clearance of phytochemicals make their low plasma concentration in clinical trials. The application of polymeric/ metallic nanoparticles, micelle, liposome, and solid-lipid nanoparticles has favorably overcome these pharmacokinetic limitations through enhancing cellular uptake, 


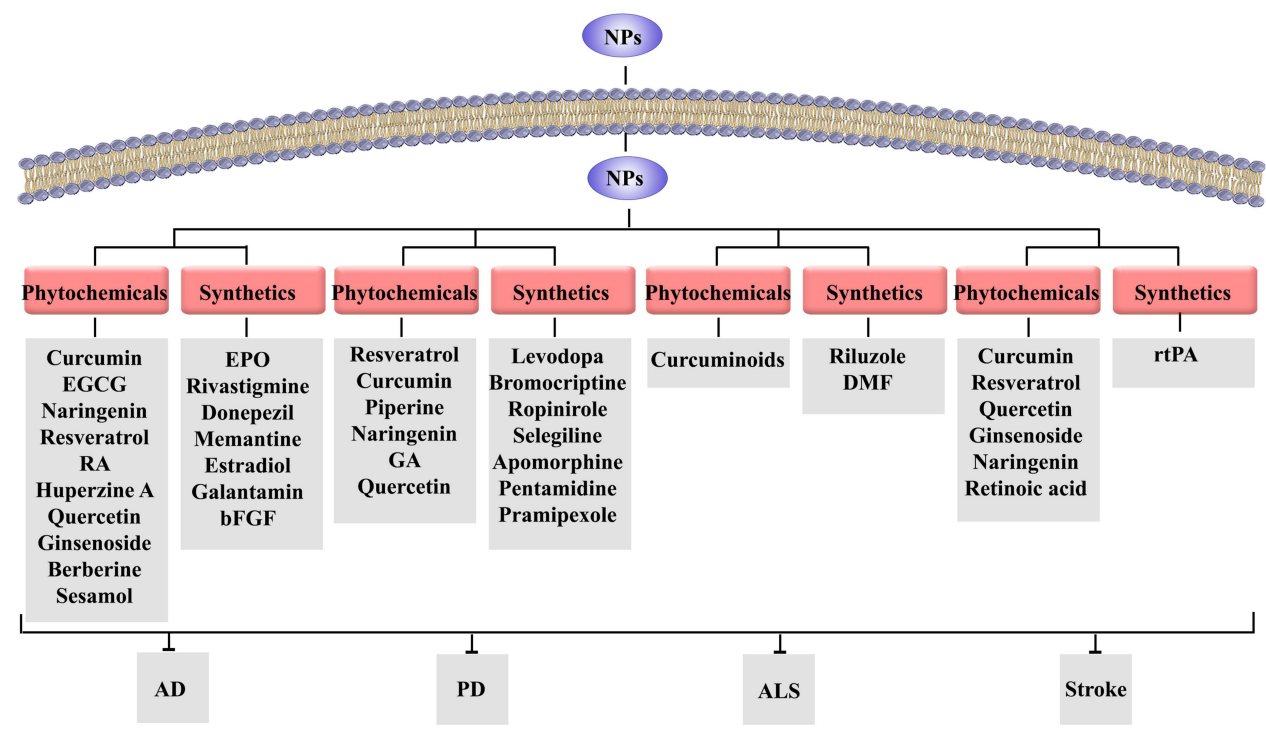

Figure 3 The potential uses of phytochemical/synthetic nanoformulations against multiple neurodegenerative diseases.

Abbreviations: AD, Alzheimer's disease; ALS, Amyotrophic lateral sclerosis; bFGF, fibroblast growth factor; EPO, erythropoietin; DMF, dimethyl fumarate; EGCG, epigallocatechin 3-gallate; GA, Gallic acid; NPs, nanoparticles; PD, Parkinson's disease; RA, rosmarinic acid; rtPA, recombinant tissue plasminogen activator.

bioavailability, efficacy and specificity of anticancer secondary metabolites. ${ }^{6,219}$

Therefore, nanoparticles have shown a new gate to pave the road in combating NDDs through their intrinsic neuroprotective effects, restricting pharmacokinetic limitations, improving biodegradability/biocompatibility, and easily passing BBB. In recent decades, novel delivery systems of conventional drugs and the application of multi-target phytochemicals used against NDDs have shown a bright future against AD, PD, ALS, stroke, HD, and MS. In this line, liposomes, metal, semiconductor, polymeric nanoparticles, SLN, NLC, and NEs, have all demonstrated their ability to improve brain transportation by more readily passing into the CNS.

The current manuscript highlights novel delivery systems of phytochemicals and synthetic drugs against

Table 3 Phytochemical/Synthetic Nanoformulations in Combating HD and MS

\begin{tabular}{|c|c|c|c|c|c|}
\hline Disease & Component & $\begin{array}{l}\text { Nano } \\
\text { Vehiclel } \\
\text { Method }\end{array}$ & Study Types & Results & References \\
\hline \multirow[t]{3}{*}{ HD } & \multicolumn{5}{|c|}{ Phytochemicals Nanoformulations } \\
\hline & Curcumin & SLN & In vivo: female Wistar Rats & $\uparrow$ bioavailability, $\uparrow \mathrm{GSH}, \uparrow S O D$ & {$[211]$} \\
\hline & $\begin{array}{l}\text { Rosmarinic } \\
\text { acid }\end{array}$ & SLN & In vitro/in vivo: Wistar rat & $\begin{array}{l}\downarrow 3 \text {-NP-induced impairments, } \downarrow \text { oxidative stress } \\
\text { through } \uparrow G S H \text { and CAT, } \uparrow \text { brain medication } \\
\text { concentration }\end{array}$ & {$[213]$} \\
\hline \multirow[t]{4}{*}{ MS } & \multicolumn{5}{|c|}{ Nanoformulations of Synthetics Drugs } \\
\hline & \multirow{3}{*}{$\begin{array}{l}\text { Dimethyl } \\
\text { fumarate }\end{array}$} & Nanocarriers & In vivo: Laca mice & $\downarrow$ dosage frequency & {$[215]$} \\
\hline & & SLN & $\begin{array}{l}\text { In vitro: SH-SY5Y cells; In vivo: } \\
\text { Wistar rats }\end{array}$ & $\begin{array}{l}\uparrow \text { bioavailability, } \uparrow \text { biological residence, } \uparrow \text { brain } \\
\text { absorption }\end{array}$ & [216] \\
\hline & & SLN & $\begin{array}{l}\text { In vitro: mouse brain microvascular } \\
\text { endothelial cells; In vivo: Male, } \\
\text { athymic mice }\end{array}$ & $\uparrow$ permeability values and brain absorption & [217] \\
\hline
\end{tabular}

Abbreviations: $\uparrow$, increase or upregulation; $\downarrow$, decrease or downregulation; 3-NP, 3-nitropropionic-acid; CAT, catalase; GSH, glutathione; HD, Huntington's disease; MS, multiple sclerosis; NP, nanoparticles; SLNs, solid lipid nanoparticles; SOD, superoxide dismutase. 


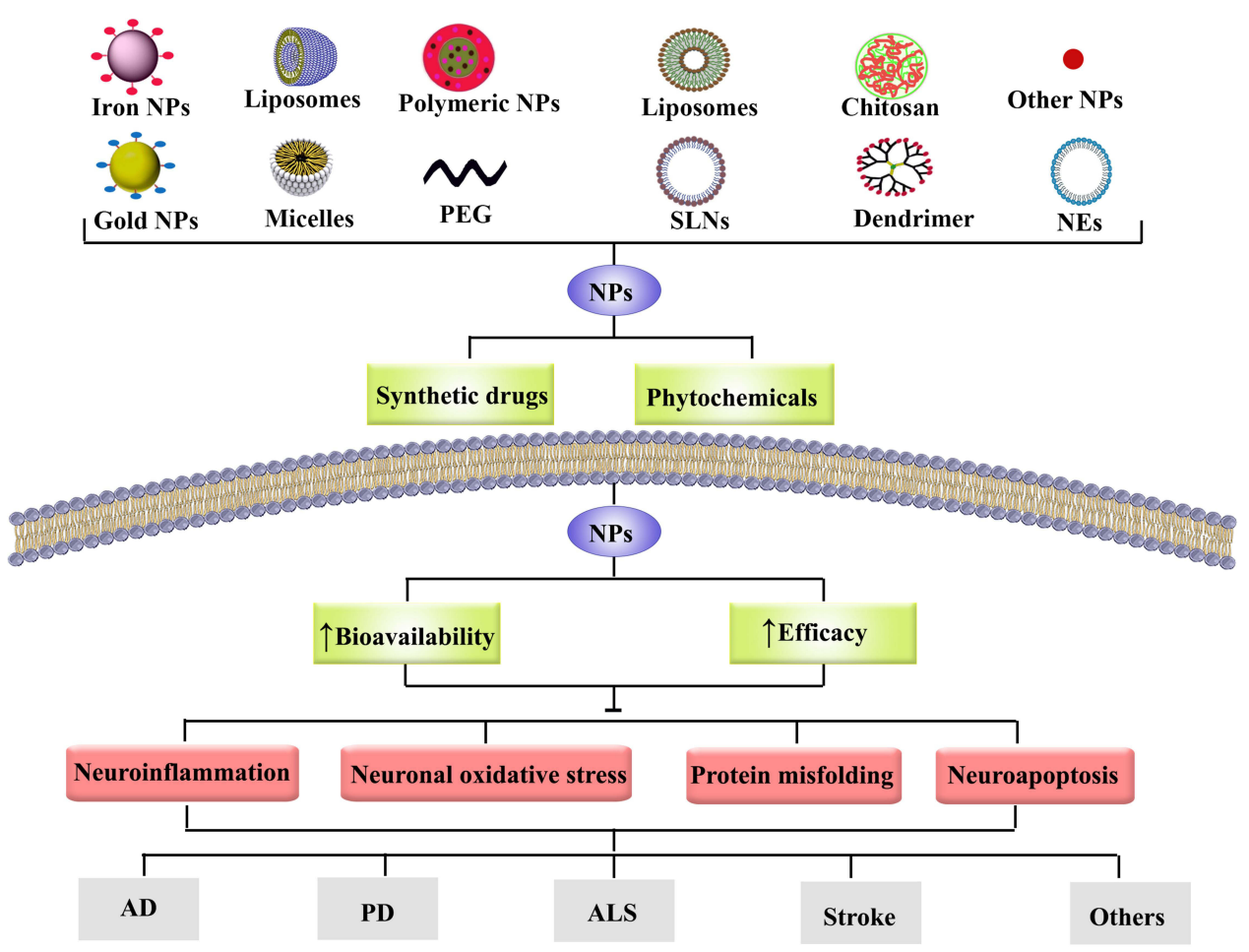

Figure 4 Nanophytochemicals and nanosynthetic drugs pave the road in combating neurodegenerative diseases, targeting different dysregulated mechanisms. Abbreviations: AD, Alzheimer's disease; ALS, Amyotrophic lateral sclerosis; NEs, nanoemulsions; NPs, nanoparticles; PD, Parkinson's disease; PEG, polyethylene glycol; SLNs, solid lipid nanoparticles.

NDDs. Such studies may reshape the therapeutic strategies in the prevention/treatment of NDDs, towards novel delivery systems of plant-derived secondary metabolites and synthetic drugs that target central dysregulated mechanisms possessing higher efficacy and a lower rate of side effects/drug resistance. Although there are yet some concerns on the neurotoxicity of novel delivery systems, which requested additional studies. ${ }^{220}$ Further pre-clinical studies are needed to elucidate the precise tools and evaluate additional suitable novel systems (eg, peptide engineering techniques, DNA nanocages, nanoenzymes) against cancer chemoresistance. Besides, alternative therapies against NDDs and wellcontrolled clinical trials for possible applicability and neurotoxicity of delivery systems are critical steps in combating cancer.

\section{Highlights}

- Oxidative stress, inflammation, apoptosis, and protein aggregation are critical dysregulated pathways in neurodegenerative diseases (NDDs)

- Some nanoformulations have shown neuroprotective effects through anti-protein aggregation, antioxidant, anti-inflammatory, and antiapoptotic roles
- Nano delivery systems drawback the pharmacokinetic limitation of phytochemicals and synthetic drugs and augment the efficacy of neuroprotective agents

- The nanoformulations of phytochemicals and synthetic drugs critically modulate multiple dysregulated pathways in NDDs

- The neurotoxicity of some novel delivery systems requests for additional pre-clinical studies

\section{Acknowledgments}

This research did not receive any specific grant from funding agencies in the public, commercial, or not-forprofit sectors.

\section{Author Contributions}

All authors made a significant contribution to the work reported, whether that is in the conception, study design, execution, acquisition of data, analysis and interpretation, or in all these areas; took part in drafting, revising or critically reviewing the article; gave final approval of the version to be published; have agreed on the journal to which the article has been submitted; and agree to be accountable for all aspects of the work. 


\section{Disclosure}

The authors report no conflicts of interest in this work.

\section{References}

1. Moradi SZ, Momtaz S, Bayrami Z, Farzaei MH, Abdollahi M. Nanoformulations of herbal extracts in treatment of neurodegenerative disorders. Front Bioeng Biotechnol. 2020;8:238. doi: $10.3389 /$ fbioe. 2020.00238

2. Kumar H, Bhardwaj K, Nepovimova E, et al. Antioxidant functionalized nanoparticles: a combat against oxidative stress. Nanomaterials. 2020;10(7):1334. doi:10.3390/nano10071334

3. Gupta J, Fatima MT, Islam Z, Khan RH, Uversky VN, Salahuddin P. Nanoparticle formulations in the diagnosis and therapy of Alzheimer's disease. Int J Biol Macromol. 2019;130:515-526. doi:10.1016/j.ijbiomac.2019.02.156

4. Mechan A, Yuan J, Hatzidimitriou G, Irvine RJ, McCann UD, Ricaurte GA. Pharmacokinetic profile of single and repeated oral doses of MDMA in squirrel monkeys: relationship to lasting effects on brain serotonin neurons. Neuropsychopharmacology. 2006;31(2):339-350. doi:10.1038/sj.npp.1300808

5. Agarwal H, Nakara A, Shanmugam VK. Anti-inflammatory mechanism of various metal and metal oxide nanoparticles synthesized using plant extracts: a review. Biomed Pharmacother. 2019;109:2561-2572. doi:10.1016/j.biopha.2018.11.116

6. Fakhri S, Moradi SZ, Farzaei MH, Bishayee A. Modulation of Dysregulated Cancer Metabolism by Plant Secondary Metabolites: A Mechanistic Review. Elsevier; 2020.

7. Ma -D-D, Yang W-X. Engineered nanoparticles induce cell apoptosis: potential for cancer therapy. Oncotarget. 2016;7(26):40882. doi:10.18632/oncotarget.8553

8. Ross C, Taylor M, Fullwood N, Allsop D. Liposome delivery systems for the treatment of Alzheimer's disease. Int $J$ Nanomedicine. 2018;13:8507. doi:10.2147/IJN.S183117

9. Moghaddam RH, Samimi Z, Moradi SZ, Little PJ, Xu S, Farzaei $\mathrm{MH}$. Naringenin and naringin in cardiovascular disease prevention: a preclinical review. Eur J Pharmacol. 2020;887:173535. doi:10.1016/j.ejphar.2020.173535

10. Fakhri S, Pesce M, Patruno A, et al. Attenuation of Nrf2/Keap1/ ARE in Alzheimer's disease by plant secondary metabolites: a mechanistic review. Molecules. 2020;25(21):4926. doi:10.3390/ molecules 25214926

11. Moradi SZ, Jalili F, Farhadian N, et al. Polyphenols and neurodegenerative diseases: focus on neuronal regeneration. Crit Rev Food Sci Nutr. 2020:1-16. doi:10.1080/10408398.2020.1865870

12. Milatovic D, Zaja-Milatovic S, Breyer RM, Aschner M, Montine TJ. Neuroinflammation and oxidative injury in developmental neurotoxicity. In: Reproductive and Developmental Toxicology. Elsevier; 2017:1051-1061.

13. DiSabato DJ, Quan N, Godbout JP. Neuroinflammation: the devil is in the details. $J$ Neurochem. 2016;139:136-153. doi:10.1111/ jnc. 13607

14. Fricker M, Tolkovsky AM, Borutaite V, Coleman M, Brown GC. Neuronal cell death. Physiol Rev. 2018;98(2):813-880. doi:10.1152/physrev.00011.2017

15. Abbaszadeh F, Fakhri S, Khan H. Targeting apoptosis and autophagy following spinal cord injury: therapeutic approaches to polyphenols and candidate phytochemicals. Pharmacol Res. 2020;160:105069. doi:10.1016/j.phrs.2020.105069

16. Ayaz M, Sadiq A, Junaid M, Ullah F, Subhan F, Ahmed J. Neuroprotective and anti-aging potentials of essential oils from aromatic and medicinal plants. Front Aging Neurosci. 2017;9:168.

17. Nowacek A, Kosloski LM, Gendelman HE. Neurodegenerative disorders and nanoformulated drug development. Nanomedicine. 2009;4(5):541-555. doi:10.2217/nnm.09.37
18. Re F, Gregori M, Masserini M. Nanotechnology for neurodegenerative disorders. Maturitas. 2012;73(1):45-51. doi:10.1016/j. maturitas.2011.12.015

19. Wilson B, Geetha KM. Neurotherapeutic applications of nanomedicine for treating Alzheimer's disease. $J$ Control Release. 2020;325:25-37. doi:10.1016/j.jconrel.2020.05.044

20. Sim TM, Tarini D, Dheen ST, Bay BH, Srinivasan DK Nanoparticle-based technology approaches to the management of neurological disorders. Int J Mol Sci. 2020;21(17):6070. doi:10.3390/ijms21176070

21. Babazadeh A, Vahed FM, Jafari SM. Nanocarrier-mediated brain delivery of bioactives for treatment/prevention of neurodegenerative diseases. J Control Release. 2020;321:211-221. doi:10.1016/ j.jconrel.2020.02.015

22. Wang G, Rayner S, Chung R, Shi B, Liang X. Advances in nanotechnology-based strategies for the treatments of amyotrophic lateral sclerosis. Mater Today Bio. 2020;6:100055. doi:10.1016/j.mtbio.2020.100055

23. Ahmadi M, Agah E, Nafissi S, et al. Safety and efficacy of nanocurcumin as add-on therapy to riluzole in patients with amyotrophic lateral sclerosis: a pilot randomized clinical trial. Neurotherapeutics. 2018;15(2):430-438. doi:10.1007/s13311-018-0606-7

24. Mutoh T, Mutoh T, Taki Y, Ishikawa T. Therapeutic potential of natural product-based oral nanomedicines for stroke prevention. $J$ Med Food. 2016;19(6):521-527. doi:10.1089/jmf.2015.3644

25. Bernardo-Castro S, Albino I, Barrera-Sandoval ÁM, et al. Therapeutic nanoparticles for the different phases of ischemic stroke. Life. 2021;11(6):482. doi:10.3390/life11060482

26. Sarmah D, Saraf J, Kaur H, et al. Stroke management: an emerging role of nanotechnology. Micromachines. 2017;8(9):262.

27. Zeng Y, Li Z, Zhu H, Gu Z, Zhang H, Luo K. Recent advances in nanomedicines for multiple sclerosis therapy. ACS Appl Bio Mater. 2020;3(10):6571-6597. doi:10.1021/acsabm.0c00953

28. Mukherjee S, Madamsetty VS, Bhattacharya D, Roy Chowdhury S, Paul MK, Mukherjee A. Recent advancements of nanomedicine in neurodegenerative disorders theranostics. Adv Funct Mater. 2020;30(35):2003054. doi:10.1002/adfm.202003054

29. Gao H, Pang Z, Jiang X. Targeted delivery of nano-therapeutics for major disorders of the central nervous system. Pharm Res. 2013;30(10):2485-2498. doi:10.1007/s11095-013-1122-4

30. Asil SM, Ahlawat J, Barroso GG, Narayan M. Nanomaterial based drug delivery systems for the treatment of neurodegenerative diseases. Biomater Sci. 2020;8(15):4109-4128. doi:10.1039/D0BM00809E

31. Calzoni E, Cesaretti A, Polchi A, Di Michele A, Tancini B, Emiliani C. Biocompatible polymer nanoparticles for drug delivery applications in cancer and neurodegenerative disorder therapies. J Funct Biomater. 2019;10(1):4. doi:10.3390/jfb10010004

32. An HW, Mamuti M, Wang X, et al. Rationally Designed Modular Drug Delivery Platform Based on Intracellular Peptide Selfassembly. Wiley Online Library; 2021:20210153.

33. Zhang R, Yan X, Fan K. The advances of nanozyme in brain disease. In: Nanomedicine in Brain Diseases; 2019:139-179.

34. Fakhri S, Piri S, Moradi SZ, Khan H. Phytochemicals targeting oxidative stress, interconnected neuroinflammatory and neuroapoptotic pathways following radiation. Curr Neuropharmacol. 2021;19. doi:10.2174/1570159X19666210809103346

35. Tee JK, Ong CN, Bay BH, Ho HK, Leong DT. Oxidative stress by inorganic nanoparticles. WIREs Nanomed Nanobiotechnol. 2016;8(3):414-438. doi:10.1002/wnan.1374

36. Manke A, Wang L, Rojanasakul Y. Mechanisms of nanoparticleinduced oxidative stress and toxicity. Biomed Res Int. 2013;2013:1-15. doi:10.1155/2013/942916

37. Eriksson P, Tal AA, Skallberg A, et al. Cerium oxide nanoparticles with antioxidant capabilities and gadolinium integration for MRI contrast enhancement. Sci Rep. 2018;8(1):6999. doi:10. 1038/s41598-018-25390-z 
38. Caputo F, De Nicola M, Sienkiewicz A, et al. Cerium oxide nanoparticles, combining antioxidant and UV shielding properties, prevent UV-induced cell damage and mutagenesis. Nanoscale. 2015;7(38):15643-15656. doi:10.1039/C5NR03767K

39. Ragg R, Schilmann AM, Korschelt K, et al. Intrinsic superoxide dismutase activity of $\mathrm{MnO}$ nanoparticles enhances the magnetic resonance imaging contrast. J Mater Chem B. 2016;4(46):74237428. doi:10.1039/C6TB02078J

40. Niu J, Azfer A, Rogers LM, Wang X, Kolattukudy PE. Cardioprotective effects of cerium oxide nanoparticles in a transgenic murine model of cardiomyopathy. Cardiovasc Res. 2007;73 (3):549-559. doi:10.1016/j.cardiores.2006.11.031

41. Yun X, Maximov VD, Yu J, Vertegel AA, Kindy MS. Nanoparticles for targeted delivery of antioxidant enzymes to the brain after cerebral ischemia and reperfusion injury. $J$ Cereb Blood Flow Metab. 2013;33(4):583-592. doi:10.1038/ jcbfm.2012.209

42. Xu Y, Liu H, Song L. Novel drug delivery systems targeting oxidative stress in chronic obstructive pulmonary disease: a review. J Nanobiotechnology. 2020;18(1):145. doi:10.1186/ s12951-020-00703-5

43. Gil D, Rodriguez J, Ward B, Vertegel A, Ivanov V, Reukov V. Antioxidant activity of SOD and catalase conjugated with nanocrystalline ceria. Bioengineering. 2017;4(1):18. doi:10.3390/ bioengineering 4010018

44. Reddy MK, Labhasetwar V. Nanoparticle-mediated delivery of superoxide dismutase to the brain: an effective strategy to reduce ischemia-reperfusion injury. FASEB J. 2009;23(5):1384-1395. doi:10.1096/fj.08-116947

45. Reddy MK, Wu L, Kou W, Ghorpade A, Labhasetwar V. Superoxide dismutase-loaded PLGA nanoparticles protect cultured human neurons under oxidative stress. Appl Biochem Biotechnol. 2008;151(2):565. doi:10.1007/s12010-008-8232-1

46. Castellani S, Trapani A, Spagnoletta A, et al. Nanoparticle delivery of grape seed-derived proanthocyanidins to airway epithelial cells dampens oxidative stress and inflammation. $J$ Transl Med. 2018;16(1):140. doi:10.1186/s12967-018-1509-4

47. Kajita M, Hikosaka K, Iitsuka M, Kanayama A, Toshima N, Miyamoto Y. Platinum nanoparticle is a useful scavenger of superoxide anion and hydrogen peroxide. Free Radic Res. 2007;41(6):615-626. doi:10.1080/10715760601169679

48. Mauricio MD, Guerra-Ojeda S, Marchio P, et al. Nanoparticles in medicine: a focus on vascular oxidative stress. Oxid Med Cell Longev. 2018;2018:6231482. doi:10.1155/2018/6231482

49. Singhal A, Morris VB, Labhasetwar V, Ghorpade A. Nanoparticle-mediated catalase delivery protects human neurons from oxidative stress. Cell Death Dis. 2013;4(11):e903-e903. doi:10.1038/cddis.2013.362

50. Martín R, Menchón C, Apostolova N, et al. Nano-jewels in biology. Gold and platinum on diamond nanoparticles as antioxidant systems against cellular oxidative stress. ACS Nano. 2010;4 (11):6957-6965. doi:10.1021/nn1019412

51. Milatovic D, Zaja-Milatovic S, Breyer RM, Aschner M, Montine TJ. Chapter 64 - Neuroinflammation and oxidative injury in developmental neurotoxicity. In: Gupta RC, editor. Reproductive and Developmental Toxicology. Academic Press; 2011:847-854.

52. Hawkins BT, Davis TP. The blood-brain barrier/neurovascular unit in health and disease. Pharmacol Rev. 2005;57(2):173-185. doi:10.1124/pr.57.2.4

53. Shih R-H, Wang C-Y, Yang C-M. NF-kappaB signaling pathways in neurological inflammation: a mini review. Mini review. Front Mol Neurosci. 2015;8(77). doi:10.3389/fnmol.2015.00077

54. Kim M-H, Jeong H-J. Zinc oxide nanoparticles suppress LPSinduced NF- $\mathrm{KB}$ activation by inducing A20, a negative regulator of NF-kB, in RAW 264.7 macrophages. $J$ Nanosci Nanotechnol. 2015;15(9):6509-6515. doi:10.1166/jnn.2015.10319
55. Kim M-H, Seo J-H, Kim H-M, Jeong H-J. Aluminum-doped zinc oxide nanoparticles attenuate the TSLP levels via suppressing caspase-1 in activated mast cells. J Biomater Appl. 2016;30 (9):1407-1416. doi:10.1177/0885328216629822

56. Sumbayev VV, Yasinska IM, Garcia CP, et al. Gold nanoparticles downregulate interleukin-1 $\beta$-induced pro-inflammatory responses. Small. 2013;9(3):472-477. doi:10.1002/smll.201201528

57. de Carvalho TG, Garcia VB, de Araújo AA, et al. Spherical neutral gold nanoparticles improve anti-inflammatory response, oxidative stress and fibrosis in alcohol-methamphetamine-induced liver injury in rats. Int $J$ Pharm. 2018;548(1):1-14. doi:10.1016/j. ijpharm.2018.06.008

58. Shaikh S, Nazam N, Danish Rizvi SM, Hussain T, Farhana A, Choi I. Anti-amyloid aggregating gold nanoparticles: can they really be translated from bench to bedside for Alzheimer's disease treatment? Curr Protein Pept Sci. 2020;21(12):1184-1192. doi:10.2174/1389203721666200226101930

59. Yang T, Yao Q, Cao F, Liu Q, Liu B, Wang X-H. Silver nanoparticles inhibit the function of hypoxia-inducible factor-1 and target genes: insight into the cytotoxicity and antiangiogenesis. Int J Nanomedicine. 2016;11:6679. doi:10.2147/IJN.S109695

60. Sheikpranbabu S, Kalishwaralal K, Venkataraman D, Eom SH, Park J, Gurunathan S. Silver nanoparticles inhibit VEGF-and IL$1 \beta$-induced vascular permeability via Src dependent pathway in porcine retinal endothelial cells. J Nanobiotechnology. 2009;7 (1):1-12. doi:10.1186/1477-3155-7-8

61. Jang S, Park JW, Cha HR, et al. Silver nanoparticles modify VEGF signaling pathway and mucus hypersecretion in allergic airway inflammation. Int $J$ Nanomedicine. 2012;7:1329. doi:10.2147/IJN.S27159

62. Franková J, Pivodová V, Vágnerová H, Juráňová J, Ulrichová J. Effects of silver nanoparticles on primary cell cultures of fibroblasts and keratinocytes in a wound-healing model. $J$ Appl Biomater Funct Mater. 2016;14(2):137-142. doi:10.5301/ jabfm. 5000268

63. Zhu C, Zhang S, Song C, et al. Selenium nanoparticles decorated with Ulva lactuca polysaccharide potentially attenuate colitis by inhibiting NF- $\mathrm{KB}$ mediated hyper inflammation. $J$ Nanobiotechnol. 2017;15(1):1-15. doi:10.1186/s12951-017-0252-y

64. Seisenbaeva GA, Fromell K, Vinogradov VV, et al. Dispersion of TiO 2 nanoparticles improves burn wound healing and tissue regeneration through specific interaction with blood serum proteins. Sci Rep. 2017;7(1):1-11. doi:10.1038/s41598-017-15792-w

65. Fiorani L, Passacantando M, Santucci S, Di Marco S, Bisti S, Maccarone R. Cerium oxide nanoparticles reduce microglial activation and neurodegenerative events in light damaged retina. PLoS One. 2015;10(10):e0140387. doi:10.1371/journal.pone.0140387

66. Xue J, Liu T, Liu Y, et al. Neuroprotective effect of biosynthesised gold nanoparticles synthesised from root extract of Paeonia moutan against Parkinson disease - in vitro \& In vivo model. $J$ Photochem Photobiol B. 2019;200:111635. doi:10.1016/j. jphotobiol.2019.111635

67. Park SY, Yi EH, Kim Y, Park G. Anti-neuroinflammatory effects of Ephedra sinica Stapf extract-capped gold nanoparticles in microglia. Int J Nanomedicine. 2019;14:2861. doi:10.2147/IJN. S195218

68. Murad U, Khan SA, Ibrar M, Ullah S, Khattak U. Synthesis of silver and gold nanoparticles from leaf of Litchi chinensis and its biological activities. Asian Pac J Trop Biomed. 2018;8(3):142. doi:10.4103/2221-1691.227995

69. Govindappa M, Hemashekhar B, Arthikala M-K, Ravishankar Rai V, Ramachandra YL. Characterization, antibacterial, antioxidant, antidiabetic, anti-inflammatory and antityrosinase activity of green synthesized silver nanoparticles using Calophyllum tomentosum leaves extract. Results Phys. 2018;9:400-408. doi:10.1016/j.rinp.2018.02.049 
70. Erjaee H, Nazifi S, Rajaian H. Effect of Ag-NPs synthesised by Chamaemelum nobile extract on the inflammation and oxidative stress induced by carrageenan in mice paw. IET Nanobiotechnol. 2017;11(6):695-701. doi:10.1049/iet-nbt.2016.0245

71. Muniyappan N, Nagarajan NS. Green synthesis of silver nanoparticles with Dalbergia spinosa leaves and their applications in biological and catalytic activities. Process Biochem. 2014;49 (6):1054-1061. doi:10.1016/j.procbio.2014.03.015

72. David L, Moldovan B, Vulcu A, et al. Green synthesis, characterization and anti-inflammatory activity of silver nanoparticles using European black elderberry fruits extract. Colloids Surf B Biointerfaces. 2014;122:767-777. doi:10.1016/j.colsurfb.2014. 08.018

73. Mohamed El-Rafie H, Abdel-Aziz Hamed M. Antioxidant and anti-inflammatory activities of silver nanoparticles biosynthesized from aqueous leaves extracts of four Terminalia species. Adv Nat Sci: Nanosci Nanotechnol. 2014;5(3):035008. doi:10.1088/2043$6262 / 5 / 3 / 035008$

74. Wang Y, Li S-Y, Shen S, Wang J. Protecting neurons from cerebral ischemia/reperfusion injury via nanoparticle-mediated delivery of an siRNA to inhibit microglial neurotoxicity. Biomaterials. 2018;161:95-105. doi:10.1016/j.biomaterials.2018. 01.039

75. Yuan X, Fu Z, Ji P, et al. Selenium nanoparticles pre-treatment reverse behavioral, oxidative damage, neuronal loss and neurochemical alterations in pentylenetetrazole-induced epileptic seizures in mice. Int J Nanomedicine. 2020;15:6339. doi:10.2147/ IJN.S259134

76. Andrabi SS, Yang J, Gao Y, Kuang Y, Labhasetwar V. Nanoparticles with antioxidant enzymes protect injured spinal cord from neuronal cell apoptosis by attenuating mitochondrial dysfunction. J Control Release. 2020;317:300-311. doi:10.1016/j. jconrel.2019.12.001

77. Nazarian S, Abdolmaleki Z, Torfeh A, Beheshtiha SHS. Mesenchymal stem cells with modafinil (gold nanoparticles) significantly improves neurological deficits in rats after middle cerebral artery occlusion. Exp Brain Res. 2020;238(11):2589-2601. doi:10.1007/s00221-020-05913-9

78. Petro M, Jaffer H, Yang J, Kabu S, Morris VB, Labhasetwar V. Tissue plasminogen activator followed by antioxidant-loaded nanoparticle delivery promotes activation/mobilization of progenitor cells in infarcted rat brain. Biomaterials. 2016;81:169180. doi:10.1016/j.biomaterials.2015.12.009

79. Küçükdoğru R, Türkez H, Arslan ME, et al. Neuroprotective effects of boron nitride nanoparticles in the experimental Parkinson's disease model against MPP+ induced apoptosis. Metab Brain Dis. 2020;35(6):947-957. doi:10.1007/s11011-02000559-6

80. Puzzo D, Gulisano W, Palmeri A, Arancio O. Rodent models for Alzheimer's disease drug discovery. Expert Opin Drug Discov. 2015;10(7):703-711. doi:10.1517/17460441.2015.1041913

81. Espay AJ, Vizcarra JA, Marsili L, et al. Revisiting protein aggregation as pathogenic in sporadic Parkinson and Alzheimer diseases. Neurology. 2019;92(7):329-337. doi:10.1212/WNL.00 00000000006926

82. Khanam H, Ali A, Asif M. Neurodegenerative diseases linked to misfolded proteins and their therapeutic approaches: a review. Eur J Med Chem. 2016;124:1121-1141. doi:10.1016/j.ejmech. 2016.08.006

83. Jiang T, Yu J-T, Tian Y, Tan L. Epidemiology and etiology of Alzheimer's disease: from genetic to non-genetic factors. Curr Alzheimer Res. 2013;10(8):852-867. doi:10.2174/15672050113 109990155

84. Haass C, Selkoe DJ. Soluble protein oligomers in neurodegeneration: lessons from the Alzheimer's amyloid $\beta$-peptide. Nat Rev Mol Cell Biol. 2007;8(2):101-112. doi:10.1038/nrm2101
85. Iwai A, Masliah E, Yoshimoto M, et al. The precursor protein of non-A $\beta$ component of Alzheimer's disease amyloid is a presynaptic protein of the central nervous system. Neuron. 1995;14 (2):467-475. doi:10.1016/0896-6273(95)90302-X

86. Singleton A, Farrer M, Johnson J, et al. [alpha]-synuclein locus triplication causes Parkinson's disease. science. 2003;302 (5646):841-842. doi:10.1126/science.1090278

87. Sontheimer H. Diseases of the Nervous System. Academic Press; 2015.

88. Wingo TS, Cutler DJ, Yarab N, Kelly CM, Glass JD. The heritability of amyotrophic lateral sclerosis in a clinically ascertained United States research registry. PLoS One. 2011;6(11):e27985. doi:10.1371/journal.pone.0027985

89. Battistini S, Ricci C, Lotti EM, et al. Severe familial ALS with a novel exon 4 mutation (L106F) in the SOD1 gene. J Neurol Sci. 2010;293(1-2):112-115. doi:10.1016/j.jns.2010.03.009

90. Parakh S, Atkin JD. Protein folding alterations in amyotrophic lateral sclerosis. Brain Res. 2016;1648:633-649. doi:10.1016/j. brainres.2016.04.010

91. Robberecht W, Philips T. The changing scene of amyotrophic lateral sclerosis. Nat Rev Neurosci. 2013;14(4):248-264. doi:10.1038/nrn3430

92. Sweeney P, Park H, Baumann M, et al. Protein misfolding in neurodegenerative diseases: implications and strategies. Transl Neurodegener. 2017;6(1):6. doi:10.1186/s40035-017-0077-5

93. Gonzalez-Garcia M, Fusco G, De Simone A. Membrane interactions and toxicity by misfolded protein oligomers. Review. Front Cell Dev Biol. 2021;9(395). doi:10.3389/fcell.2021.64 2623

94. Folch J, Ettcheto M, Petrov D, et al. Review of the advances in treatment for Alzheimer disease: strategies for combating $\beta$-amyloid protein. Neurología (English Edition). 2018;33(1):47-58. doi:10.1016/j.nrleng.2015.03.019

95. Yang W, Wang L, Mettenbrink EM, DeAngelis PL, Wilhelm S. Nanoparticle toxicology. Annu Rev Pharmacol Toxicol. 2021;61 (1):269-289. doi:10.1146/annurev-pharmtox-032320-110338

96. Rivera Gil P, Oberdörster G, Elder A, Puntes V, Parak WJ. Correlating physico-chemical with toxicological properties of nanoparticles: the present and the future. ACS Nano. 2010;4 (10):5527-5531. doi:10.1021/nn1025687

97. Elsaesser A, Howard CV. Toxicology of nanoparticles. Adv Drug Deliv Rev. 2012;64(2):129-137. doi:10.1016/j.addr.2011.09.001

98. Fu PP, Xia Q, Hwang H-M, Ray PC, Yu H. Mechanisms of nanotoxicity: generation of reactive oxygen species. J Food Drug Anal. 2014;22(1):64-75. doi:10.1016/j.jfda.2014.01.005

99. Chen KL, Bothun GD. Nanoparticles Meet Cell Membranes: Probing Nonspecific Interactions Using Model Membranes. ACS Publications; 2014.

100. Nel A, Xia T, Mädler L, Li N. Toxic potential of materials at the nanolevel. science. 2006;311(5761):622-627. doi:10.1126/ science. 1114397

101. Abdal Dayem A, Hossain MK, Lee SB, et al. The role of reactive oxygen species (ROS) in the biological activities of metallic nanoparticles. Int J Mol Sci. 2017;18(1):120. doi:10.3390/ ijms 18010120

102. Xia T, Kovochich M, Brant J, et al. Comparison of the abilities of ambient and manufactured nanoparticles to induce cellular toxicity according to an oxidative stress paradigm. Nano Lett. 2006;6 (8):1794-1807. doi:10.1021/n1061025k

103. Teleanu DM, Chircov C, Grumezescu AM, Teleanu RI. Neurotoxicity of nanomaterials: an up-to-date overview. Nanomaterials (Basel). 2019;9(1):96. doi:10.3390/nano9010096

104. Yuan ZY, Hu YL, Gao JQ. Brain localization and neurotoxicity evaluation of polysorbate 80 -modified chitosan nanoparticles in rats. PLoS One. 2015;10(8):e0134722. doi:10.1371/journal.pone. 0134722 
105. Huo T, Barth RF, Yang W, et al. Preparation, biodistribution and neurotoxicity of liposomal cisplatin following convection enhanced delivery in normal and F98 glioma bearing rats. PLoS One. 2012;7(11):e48752-e48752. doi:10.1371/journal.pone.0048 752

106. Zeng Y, Kurokawa Y, Win-Shwe TT, et al. Effects of PAMAM dendrimers with various surface functional groups and multiple generations on cytotoxicity and neuronal differentiation using human neural progenitor cells. J Toxicol Sci. 2016;41(3):351370. doi: $10.2131 /$ jts. 41.351

107. Yarjanli Z, Ghaedi K, Esmaeili A, Rahgozar S, Zarrabi A. Iron oxide nanoparticles may damage to the neural tissue through iron accumulation, oxidative stress, and protein aggregation. BMC Neurosci. 2017;18(1):51. doi:10.1186/s12868-017-0369-9

108. Sun C, Yin N, Wen R, et al. Silver nanoparticles induced neurotoxicity through oxidative stress in rat cerebral astrocytes is distinct from the effects of silver ions. Neurotoxicology. 2016;52:210-221. doi:10.1016/j.neuro.2015.09.007

109. You R, Ho Y-S, Hung CH-L, et al. Silica nanoparticles induce neurodegeneration-like changes in behavior, neuropathology, and affect synapse through MAPK activation. Part Fibre Toxicol. 2018;15(1):28. doi:10.1186/s12989-018-0263-3

110. Shi B, Du X, Chen J, et al. Multifunctional hybrid nanoparticles for traceable drug delivery and intracellular microenvironmentcontrolled multistage drug-release in neurons. Small. 2017;13 (20):1603966. doi:10.1002/smll.201603966

111. Song B, Zhang Y, Liu J, Feng X, Zhou T, Shao L. Unraveling the neurotoxicity of titanium dioxide nanoparticles: focusing on molecular mechanisms. Beilstein J Nanotechnol. 2016;7:645654. doi:10.3762/bjnano.7.57

112. Zhao Y, Wang X, Wu Q, Li Y, Wang D. Translocation and neurotoxicity of CdTe quantum dots in RMEs motor neurons in nematode Caenorhabditis elegans. J Hazard Mater. 2015;28 3:480-489. doi:10.1016/j.jhazmat.2014.09.063

113. Wu T, Zhang T, Chen Y, Tang M. Research advances on potential neurotoxicity of quantum dots. $J$ Appl Toxicol. 2016;36(3):345351. doi:10.1002/jat.3229

114. Ceña V, Játiva P. Nanoparticle crossing of blood-brain barrier: a road to new therapeutic approaches to central nervous system diseases. Future Med. 2018;13(13):1513-1516.

115. Saraiva C, Praça C, Ferreira R, Santos T, Ferreira L, Bernardino L. Nanoparticle-mediated brain drug delivery: overcoming bloodbrain barrier to treat neurodegenerative diseases. J Control Release. 2016;235:34-47. doi:10.1016/j.jconrel.2016.05.044

116. Zhou Y, Peng Z, Seven ES, Leblanc RM. Crossing the bloodbrain barrier with nanoparticles. $J$ Control Release. 2018;270:290-303. doi:10.1016/j.jconrel.2017.12.015

117. Ding S, Khan AI, Cai X, et al. Overcoming blood-brain barrier transport: advances in nanoparticle-based drug delivery strategies. Mater Today. 2020;37:112-125. doi:10.1016/j.mattod.2020.02.001

118. Pardridge WM. The blood-brain barrier: bottleneck in brain drug development. NeuroRx. 2005;2(1):3-14. doi:10.1602/neurorx. 2.1 .3

119. Reimold I, Domke D, Bender J, Seyfried CA, Radunz H-E, Fricker G. Delivery of nanoparticles to the brain detected by fluorescence microscopy. Eur J Pharm Biopharm. 2008;70 (2):627-632. doi:10.1016/j.ejpb.2008.05.007

120. Fornaguera C, Dols-Perez A, Caldero G, Garcia-Celma M, Camarasa J, Solans C. PLGA nanoparticles prepared by nanoemulsion templating using low-energy methods as efficient nanocarriers for drug delivery across the blood-brain barrier. $J$ Control Release. 2015;211:134-143. doi:10.1016/j.jconrel.2015.06.002

121. Sahni JK, Doggui S, Ali J, Baboota S, Dao L, Ramassamy C. Neurotherapeutic applications of nanoparticles in Alzheimer's disease. J Control Release. 2011;152(2):208-231. doi:10.1016/j. jconrel.2010.11.033
122. Cerqueira SR, Ayad NG, Lee JK. Neuroinflammation treatment via targeted delivery of nanoparticles. Front Cell Neurosci. 2020;14:576037. doi:10.3389/fncel.2020.576037

123. Weller J, Budson A. Current understanding of Alzheimer's disease diagnosis and treatment. F1000Research. 2018;7:1161. doi:10.12688/f1000research.14506.1

124. Teixeira MI, Lopes CM, Amaral MH, Costa PC. Current insights on lipid nanocarrier-assisted drug delivery in the treatment of neurodegenerative diseases. Eur $J$ Pharm Biopharm. 2020;149:192-217. doi:10.1016/j.ejpb.2020.01.005

125. López ES, Machado AL, Vidal LB, González-Pizarro R, Silva $\mathrm{AD}$, Souto EB. Lipid nanoparticles as carriers for the treatment of neurodegeneration associated with Alzheimer's disease and glaucoma: present and future challenges. Curr Pharm Des. 2020;26 (12):1235-1250. doi:10.2174/1381612826666200218101231

126. Loureiro JA, Andrade S, Duarte A, et al. Resveratrol and grape extract-loaded solid lipid nanoparticles for the treatment of Alzheimer's disease. Molecules. 2017;22(2):277. doi:10.3390/ molecules 22020277

127. Rajput A, Bariya A, Allam A, Othman S, Butani SB. In situ nanostructured hydrogel of resveratrol for brain targeting: in vitro-in vivo characterization. Drug Deliv Transl Res. 2018;8 (5):1460-1470. doi:10.1007/s13346-018-0540-6

128. Anand P, Kunnumakkara AB, Newman RA, Aggarwal BB. Bioavailability of curcumin: problems and promises. Mol Pharm. 2007;4(6):807-818. doi:10.1021/mp700113r

129. Cheng KK, Yeung CF, Ho SW, Chow SF, Chow AH, Baum L. Highly stabilized curcumin nanoparticles tested in an in vitro blood-brain barrier model and in Alzheimer's disease Tg2576 mice. AAPS J. 2013;15(2):324-336. doi:10.1208/s12248-012-9444-4

130. Mandal M, Jaiswal P, Mishra A. Role of curcumin and its nanoformulations in neurotherapeutics: a comprehensive review. $J$ Biochem Mol Toxicol. 2020;34(6):e22478. doi:10.1002/jbt.22478

131. Doggui S, Sahni JK, Arseneault M, Dao L, Ramassamy C. Neuronal uptake and neuroprotective effect of curcumin-loaded PLGA nanoparticles on the human SK-N-SH cell line. J Alzheimers Dis. 2012;30 (2):377-392. doi:10.3233/JAD-2012-112141

132. Barbara R, Belletti D, Pederzoli F, et al. Novel curcumin loaded nanoparticles engineered for blood-brain barrier crossing and able to disrupt Abeta aggregates. Int J Pharm. 2017;526(1-2):413424. doi:10.1016/j.ijpharm.2017.05.015

133. Tiwari SK, Agarwal S, Seth B, et al. Curcumin-loaded nanoparticles potently induce adult neurogenesis and reverse cognitive deficits in Alzheimer's disease model via canonical Wnt/ $\beta$-catenin pathway. ACS Nano. 2014;8(1):76-103. doi:10.1021/nn405077y

134. Fan S, Zheng Y, Liu X, et al. Curcumin-loaded PLGA-PEG nanoparticles conjugated with B6 peptide for potential use in Alzheimer's disease. Drug Deliv. 2018;25(1):1091-1102. doi:10.1080/10717544.2018.1461955

135. Lazar AN, Mourtas S, Youssef I, et al. Curcumin-conjugated nanoliposomes with high affinity for $\mathrm{A} \beta$ deposits: possible applications to Alzheimer disease. Nanomedicine. 2013;9(5):712-721. doi:10.1016/j.nano.2012.11.004

136. Md S, Gan SY, Haw YH, Ho CL, Wong S, Choudhury H. In vitro neuroprotective effects of naringenin nanoemulsion against $\beta$ amyloid toxicity through the regulation of amyloidogenesis and tau phosphorylation. Int J Biol Macromol. 2018;118:1211-1219. doi:10.1016/j.ijbiomac.2018.06.190

137. Puerta E, Suárez-Santiago JE, Santos-Magalhães NS, Ramirez MJ, Irache JM. Effect of the oral administration of nanoencapsulated quercetin on a mouse model of Alzheimer's disease. Int $J$ Pharm. 2017;517(1-2):50-57. doi:10.1016/j.ijpharm.2016.11.061

138. Testa G, Gamba P, Badilli U, et al. Loading into nanoparticles improves quercetin's efficacy in preventing neuroinflammation induced by oxysterols. PLoS One. 2014;9(5):e96795. doi:10. 1371/journal.pone.0096795 
139. Palle S, Neerati P. Quercetin nanoparticles attenuates scopolamine induced spatial memory deficits and pathological damages in rats. Bull Fac Pharm Cairo Univ. 2017;55(1):101-106. doi:10.1016/j. bfopcu.2016.10.004

140. Sun D, Li N, Zhang W, et al. Design of PLGA-functionalized quercetin nanoparticles for potential use in Alzheimer's disease. Colloids Surf B Biointerfaces. 2016;148:116-129. doi:10.1016/j. colsurfb.2016.08.052

141. Kuo Y-C, Rajesh R. Targeted delivery of rosmarinic acid across the blood-brain barrier for neuronal rescue using polyacrylamidechitosan-poly (lactide-co-glycolide) nanoparticles with surface cross-reacting material 197 and apolipoprotein E. Int J Pharm. 2017;528(1-2):228-241. doi:10.1016/j.ijpharm.2017.05.039

142. Smith A, Giunta B, Bickford PC, Fountain M, Tan J, Shytle RD. Nanolipidic particles improve the bioavailability and $\alpha$-secretase inducing ability of epigallocatechin-3-gallate (EGCG) for the treatment of Alzheimer's disease. Int J Pharm. 2010;389(12):207-212. doi:10.1016/j.ijpharm.2010.01.012

143. Singh NA, Mandal AKA, Khan ZA. Inhibition of Al (III)-induced A $\beta 42$ fibrillation and reduction of neurotoxicity by epigallocatechin-3-gallate nanoparticles. J Biomed Nanotechnol. 2018;14 (6):1147-1158. doi:10.1166/jbn.2018.2552

144. Zhang J, Zhou X, Yu Q, et al. Epigallocatechin-3-gallate (EGCG)-stabilized selenium nanoparticles coated with Tet-1 peptide to reduce amyloid- $\beta$ aggregation and cytotoxicity. ACS Appl Mater Interfaces. 2014;6(11):8475-8487. doi:10.1021/am50 $1341 \mathrm{u}$

145. Parihar VK, Prabhakar K, Veerapur VP, et al. Effect of sesamol on radiation-induced cytotoxicity in Swiss albino mice. Mutat Res Genet Toxicol Environ Mutagen. 2006;611(1-2):9-16. doi:10.10 16/j.mrgentox.2006.06.037

146. Sachdeva AK, Misra S, Kaur IP, Chopra K. Neuroprotective potential of sesamol and its loaded solid lipid nanoparticles in ICV-STZ-induced cognitive deficits: behavioral and biochemical evidence. Eur J Pharmacol. 2015;747:132-140. doi:10.1016/j. ejphar.2014.11.014

147. Cai Z, Wang C, Yang W. Role of berberine in Alzheimer's disease. Neuropsychiatr Dis Treat. 2016;12:2509. doi:10.2147/ NDT.S114846

148. Lohan S, Raza K, Mehta S, Bhatti GK, Saini S, Singh B. AntiAlzheimer's potential of berberine using surface decorated multiwalled carbon nanotubes: a preclinical evidence. Int J Pharm. 2017;530(1-2):263-278. doi:10.1016/j.ijpharm.2017.07.080

149. Meng Q, Wang A, Hua $\mathrm{H}$, et al. Intranasal delivery of Huperzine A to the brain using lactoferrin-conjugated N-trimethylated chitosan surface-modified PLGA nanoparticles for treatment of Alzheimer's disease. Int J Nanomedicine. 2018;13:705. doi:10. 2147/IJN.S151474

150. Aalinkeel R, Kutscher HL, Singh A, et al. Neuroprotective effects of a biodegradable poly (lactic-co-glycolic acid)-ginsenoside Rg3 nanoformulation: a potential nanotherapy for Alzheimer's disease? J Drug Target. 2018;26(2):182-193. doi:10.1080/1061 186X.2017.1354002

151. Dara T, Vatanara A, Meybodi MN, et al. Erythropoietin-loaded solid lipid nanoparticles: preparation, optimization, and in vivo evaluation. Colloids Surf B Biointerfaces. 2019;178:307-316. doi:10.1016/j.colsurfb.2019.01.027

152. Ismail MF, ElMeshad AN, Salem NA-H. Potential therapeutic effect of nanobased formulation of rivastigmine on rat model of Alzheimer's disease. Int J Nanomedicine. 2013;8:393. doi:10.21 47/IJN.S39232

153. Shah B, Khunt D, Bhatt H, Misra M, Padh H. Application of quality by design approach for intranasal delivery of rivastigmine loaded solid lipid nanoparticles: effect on formulation and characterization parameters. Eur J Pharm Sci. 2015;78:54-66. doi:10.1016/j.ejps.2015.07.002
154. Al Asmari AK, Ullah Z, Tariq M, Fatani A. Preparation, characterization, and in vivo evaluation of intranasally administered liposomal formulation of donepezil. Drug Des Devel Ther. 2016;10:205. doi:10.2147/DDDT.S93937

155. Misra S, Chopra K, Sinha V, Medhi B. Galantamine-loaded solidlipid nanoparticles for enhanced brain delivery: preparation, characterization, in vitro and in vivo evaluations. Drug Deliv. 2016;23 (4):1434-1443. doi:10.3109/10717544.2015.1089956

156. Sánchez-López E, Ettcheto M, Egea MA, et al. Memantine loaded PLGA PEGylated nanoparticles for Alzheimer's disease: in vitro and in vivo characterization. J Nanobiotechnology. 2018;16(1):116. doi:10.1186/s12951-018-0356-z

157. Jamshed N, Ozair FF, Aggarwal P, Ekka M. Alzheimer disease in post-menopausal women: intervene in the critical window period. J Midlife Health. 2014;5(1):38. doi:10.4103/0976-7800.127791

158. Mittal G, Carswell H, Brett R, Currie S, Kumar MR. Development and evaluation of polymer nanoparticles for oral delivery of estradiol to rat brain in a model of Alzheimer's pathology. J Control Release. 2011;150(2):220-228. doi:10.1016/j.jconrel.2010.11.013

159. Wilcock GK, Black SE, Hendrix SB, et al. Efficacy and safety of tarenflurbil in mild to moderate Alzheimer's disease: a randomised phase II trial. Lancet Neurol. 2008;7(6):483-493. doi:10.1016/S1474-4422(08)70090-5

160. Muntimadugu E, Dhommati R, Jain A, Challa VGS, Shaheen M, Khan W. Intranasal delivery of nanoparticle encapsulated tarenflurbil: a potential brain targeting strategy for Alzheimer's disease. Eur J Pharm Sci. 2016;92:224-234. doi:10.1016/j. ejps.2016.05.012

161. Poovaiah N, Davoudi Z, Peng H, et al. Treatment of neurodegenerative disorders through the blood-brain barrier using nanocarriers Nanoscale. 2018;10(36):16962-16983. doi:10.1039/c8nr04073g

162. Zhang $\mathrm{C}$, Chen J, Feng $\mathrm{C}$, et al. Intranasal nanoparticles of basic fibroblast growth factor for brain delivery to treat Alzheimer's disease. Int J Pharm. 2014;461(1-2):192-202. doi:10.1016/j. ijpharm.2013.11.049

163. Fakhri S, Abdian S, Zarneshan SN, Akkol EK, Farzaei MH, Sobarzo-Sánchez E. Targeting mitochondria by plant secondary metabolites: a promising strategy in combating Parkinson's disease. Int J Mol Sci. 2021;22(22):12570. doi:10.3390/ijms222212570

164. Palle $S$, Neerati P. Improved neuroprotective effect of resveratrol nanoparticles as evinced by abrogation of rotenone-induced behavioral deficits and oxidative and mitochondrial dysfunctions in rat model of Parkinson's disease. Naunyn Schmiedebergs Arch Pharmacol. 2018;391(4):445-453. doi:10.1007/s00210-018-1474-8

165. Wang M, Li L, Zhang X, et al. Magnetic resveratrol liposomes as a new theranostic platform for magnetic resonance imaging guided Parkinson's disease targeting therapy. ACS Sustain Chem Eng. 2018;6(12):17124-17133. doi:10.1021/acssuschemeng.8b04507

166. Pangeni R, Sharma S, Mustafa G, Ali J, Baboota S. Vitamin E loaded resveratrol nanoemulsion for brain targeting for the treatment of Parkinson's disease by reducing oxidative stress. Nanotechnology. 2014;25(48):485102. doi:10.1088/0957-4484/25/48/485102

167. da Rocha Lindner G, Bonfanti Santos D, Colle D, et al. Improved neuroprotective effects of resveratrol-loaded polysorbate 80-coated poly (lactide) nanoparticles in MPTP-induced Parkinsonism. Nanomedicine. 2015;10(7):1127-1138. doi:10.2217/nnm.14.165

168. Kundu P, Das M, Tripathy K, Sahoo SK. Delivery of dual drug loaded lipid based nanoparticles across the blood-brain barrier impart enhanced neuroprotection in a rotenone induced mouse model of Parkinson's disease. ACS Chem Neurosci. 2016;7 (12):1658-1670. doi:10.1021/acschemneuro.6b00207

169. Gaba B, Khan T, Haider MF, et al. Vitamin E loaded naringenin nanoemulsion via intranasal delivery for the management of oxidative stress in a 6-OHDA Parkinson's disease model. Biomed Res Int. 2019;2019:1-20. doi:10.1155/2019/2382563 
170. Burgos RA, Alarcón P, Quiroga J, Manosalva C, Hancke J. Andrographolide, an anti-inflammatory multitarget drug: all roads lead to cellular metabolism. Molecules. 2020;26(1):5. doi:10.3390/molecules26010005

171. Md S, Khan RA, Mustafa G, et al. Bromocriptine loaded chitosan nanoparticles intended for direct nose to brain delivery: pharmacodynamic, pharmacokinetic and scintigraphy study in mice model. Eur J Pharm Sci. 2013;48(3):393-405. doi:10.1016/j. ejps.2012.12.007

172. Yang X, Zheng R, Cai Y, Liao M, Yuan W, Liu Z. Controlledrelease levodopa methyl ester/benserazide-loaded nanoparticles ameliorate levodopa-induced dyskinesia in rats. Int $J$ Nanomedicine. 2012;7:2077. doi:10.2147/IJN.S30463

173. Lim JH, Kim SS, Boo DH, et al. Protective effect of bromocriptine against BH4-induced Cath. a cell death involving up-regulation of antioxidant enzymes. Neurosci Lett. 2009;451(3):185-189.

174. Esposito E, Fantin M, Marti M, et al. Solid lipid nanoparticles as delivery systems for bromocriptine. Pharm Res. 2008;25 (7):1521-1530. doi:10.1007/s11095-007-9514-y

175. Barcia E, Boeva L, García-García L, et al. Nanotechnology-based drug delivery of ropinirole for Parkinson's disease. Drug Deliv. 2017;24(1):1112-1123. doi:10.1080/10717544.2017.1359862

176. Fukuzaki K, Kamenosono T, Nagata R. Effects of ropinirole on various parkinsonian models in mice, rats, and cynomolgus monkeys. Pharmacol Biochem Behav. 2000;65(3):503-508. doi:10. 1016/S0091-3057(99)00240-3

177. Pardeshi CV, Belgamwar VS, Tekade AR, Surana SJ. Novel surface modified polymer-lipid hybrid nanoparticles as intranasal carriers for ropinirole hydrochloride: in vitro, ex vivo and in vivo pharmacodynamic evaluation. J Mater Sci Mater Med. 2013;24(9):2101-2115. doi:10.1007/s10856-013-4965-7

178. Raj R, Wairkar S, Sridhar V, Gaud R. Pramipexole dihydrochloride loaded chitosan nanoparticles for nose to brain delivery: development, characterization and in vivo anti-Parkinson activity. Int $J$ Biol Macromol. 2018;109:27-35. doi:10.1016/j.ijbiomac.2017.12.056

179. Subramony JA. Apomorphine in dopaminergic therapy. Mol Pharm. 2006;3(4):380-385. doi:10.1021/mp060012c

180. Tsai M-J, Huang Y-B, Wu P-C, et al. Oral apomorphine delivery from solid lipid nanoparticles with different monostearate emulsifiers: pharmacokinetic and behavioral evaluations. J Pharm Sci. 2011;100(2):547-557. doi:10.1002/jps.22285

181. Kumar S, Dang S, Nigam K, Ali J, Baboota S. Selegiline nanoformulation in attenuation of oxidative stress and upregulation of dopamine in the brain for the treatment of Parkinson's disease. Rejuvenation Res. 2018;21(5):464 476. doi:10.1089/rej.2017.2035

182. Kumar S, Ali J, Baboota S. Design Expert ${ }^{\mathbb{B}}$ supported optimization and predictive analysis of selegiline nanoemulsion via the olfactory region with enhanced behavioural performance in Parkinson's disease. Nanotechnology. 2016;27(43):435101. doi:10.1088/0957-4484/27/43/435101

183. Rinaldi F, Seguella L, Gigli S, et al. inPentasomes: an innovative nose-to-brain pentamidine delivery blunts MPTP parkinsonism in mice. J Control Release. 2019;294:17-26. doi:10.1016/j.jconrel. 2018.12.007

184. Velander P, Wu L, Henderson F, Zhang S, Bevan DR, Xu B. Natural product-based amyloid inhibitors. Biochem Pharmacol. 2017;139:40-55. doi:10.1016/j.bcp.2017.04.004

185. Bondi M, Montana G, Craparo E, et al. Ferulic acid-loaded lipid nanostructures as drug delivery systems for Alzheimer's disease: preparation, characterization and cytotoxicity studies. Curr Nanosci. 2009;5(1):26-32. doi:10.2174/157341309787314656

186. Mohammad-Beigi H, Morshedi D, Shojaosadati SA, et al. Gallic acid loaded onto polyethylenimine-coated human serum albumin nanoparticles (PEI-HSA-GA NPs) stabilizes $\alpha$-synuclein in the unfolded conformation and inhibits aggregation. RSC Adv. 2016;6 (88):85312-85323.
187. Wang J, Xu G, Gonzales V, et al. Fibrillar inclusions and motor neuron degeneration in transgenic mice expressing superoxide dismutase 1 with a disrupted copper-binding site. Neurobiol Dis. 2002;10(2):128-138. doi:10.1006/nbdi.2002.0498

188. Bhatia NK, Srivastava A, Katyal N, et al. Curcumin binds to the pre-fibrillar aggregates of $\mathrm{Cu} / \mathrm{Zn}$ superoxide dismutase (SOD1) and alters its amyloidogenic pathway resulting in reduced cytotoxicity. Biochim Biophys Acta Proteins Proteom. 2015;1854 (5):426-436. doi:10.1016/j.bbapap.2015.01.014

189. Tripodo G, Chlapanidas T, Perteghella S, et al. Mesenchymal stromal cells loading curcumin-INVITE-micelles: a drug delivery system for neurodegenerative diseases. Colloids Surf $B$ Biointerfaces. 2015;125:300-308. doi:10.1016/j.colsurfb.2014.11. 034

190. Rothstein JD. Edaravone: a new drug approved for ALS. Cell. 2017;171(4):725. doi:10.1016/j.cell.2017.10.011

191. Yang T, Ferrill L, Gallant L, et al. Verapamil and riluzole cocktail liposomes overcome pharmacoresistance by inhibiting P-glycoprotein in brain endothelial and astrocyte cells: a potent approach to treat amyotrophic lateral sclerosis. Eur J Pharm Sci. 2018;120:30-39. doi:10.1016/j.ejps.2018.04.026

192. Silva Adaya D, Aguirre-Cruz L, Guevara J, Ortiz-Islas E. Nanobiomaterials' applications in neurodegenerative diseases. $J$ Biomater Appl. 2017;31(7):953-984. doi:10.1177/0885328216 659032

193. Battaglia L, Panciani PP, Muntoni E, et al. Lipid nanoparticles for intranasal administration: application to nose-to-brain delivery. Expert Opin Drug Deliv. 2018;15(4):369-378. doi:10.1080/ 17425247.2018.1429401

194. Marcuzzo S, Isaia D, Bonanno S, et al. FM19G11-loaded gold nanoparticles enhance the proliferation and self-renewal of ependymal stem progenitor cells derived from ALS mice. Cells. 2019;8(3):279. doi:10.3390/cells8030279

195. Nouri Z, Fakhri S, El-Senduny FF, et al. On the neuroprotective effects of naringenin: pharmacological targets, signaling pathways, molecular mechanisms, and clinical perspective. Biomolecules. 2019;9(11):690. doi:10.3390/ biom9110690

196. Lu X, Dong J, Zheng D, Li X, Ding D, Xu H. Reperfusion combined with intraarterial administration of resveratrol-loaded nanoparticles improved cerebral ischemia-reperfusion injury in rats. Nanomedicine. 2020;28:102208. doi:10.1016/j.nano.2020.102208

197. Kakkar V, Muppu SK, Chopra K, Kaur IP. Curcumin loaded solid lipid nanoparticles: an efficient formulation approach for cerebral ischemic reperfusion injury in rats. Eur J Pharm Biopharm. 2013;85(3):339-345. doi:10.1016/j.ejpb.2013.02.005

198. Ghosh A, Sarkar S, Mandal AK, Das N. Neuroprotective role of nanoencapsulated quercetin in combating ischemiareperfusion induced neuronal damage in young and aged rats. PLoS One. 2013;8(4):e57735. doi:10.1371/journal.pone. 0057735

199. Ghosh S, Sarkar S, Choudhury ST, Ghosh T, Das N. Triphenyl phosphonium coated nano-quercetin for oral delivery: neuroprotective effects in attenuating age related global moderate cerebral ischemia reperfusion injury in rats. Nanomedicine. 2017;13 (8):2439-2450. doi:10.1016/j.nano.2017.08.002

200. Zhang J, Han X, Li X, et al. Core-shell hybrid liposomal vesicles loaded with panax notoginsenoside: preparation, characterization and protective effects on global cerebral ischemia/reperfusion injury and acute myocardial ischemia in rats. Int $J$ Nanomedicine. 2012;7:4299. doi:10.2147/IJN.S32385

201. Ahmad A, Fauzia E, Kumar M, et al. Gelatin-coated polycaprolactone nanoparticle-mediated naringenin delivery rescue human mesenchymal stem cells from oxygen glucose deprivationinduced inflammatory stress. ACS Biomater Sci Eng. 2018;5 (2):683-695. doi:10.1021/acsbiomaterials.8b01081 
202. Deng J, Mei H, Shi W, et al. Recombinant tissue plasminogen activator-conjugated nanoparticles effectively targets thrombolysis in a rat model of middle cerebral artery occlusion. Curr Med Sci. 2018;38(3):427-435. doi:10.1007/s11596-018-1896-Z

203. Fukuta T, Asai T, Yanagida Y, et al. Combination therapy with liposomal neuroprotectants and tissue plasminogen activator for treatment of ischemic stroke. FASEB J. 2017;31(5):1879-1890. doi:10.1096/fj.201601209R

204. Zhu FD, Hu YJ, Yu L, et al. Nanoparticles: a hope for the treatment of inflammation in CNS. Front Pharmacol. 2021;12:683935. doi:10.3389/fphar.2021.683935

205. Carmeliet P. Angiogenesis in life, disease and medicine. Nature. 2005;438(7070):932-936. doi:10.1038/nature04478

206. George ML, Eccles SA, Tutton MG, Abulafi AM, Swift RI. Correlation of plasma and serum vascular endothelial growth factor levels with platelet count in colorectal cancer: clinical evidence of platelet scavenging? Clin Cancer Res. 2000;6(8):3147-3152.

207. Ju R, Wen Y, Gou R, Wang Y, Xu Q. The experimental therapy on brain ischemia by improvement of local angiogenesis with tissue engineering in the mouse. Cell Transplant. 2014;23(1_suppl):8395. doi: $10.3727 / 096368914 X 684998$

208. Zhao H, Bao X-J, Wang R-Z, et al. Postacute ischemia vascular endothelial growth factor transfer by transferrin-targeted liposomes attenuates ischemic brain injury after experimental stroke in rats. Hum Gene Ther. 2011;22(2):207-215. doi:10.1089/hum.2010.111

209. Andre EM, Passirani C, Seijo B, Sanchez A, Montero-Menei CN. Nano and microcarriers to improve stem cell behaviour for neuroregenerative medicine strategies: application to Huntington's disease. Biomaterials. 2016;83:347-362. doi:10.1016/j. biomaterials.2015.12.008

210. Maiti P, Dunbar GL. Use of curcumin, a natural polyphenol for targeting molecular pathways in treating age-related neurodegenerative diseases. Int J Mol Sci. 2018;19(6):1637. doi:10.3390/ ijms 19061637

211. Sandhir R, Yadav A, Mehrotra A, Sunkaria A, Singh A, Sharma S. Curcumin nanoparticles attenuate neurochemical and neurobehavioral deficits in experimental model of Huntington's disease. Neuromolecular Med. 2014;16(1):106-118. doi:10.1007/s12017013-8261-y
212. Pepe G, Calce E, Verdoliva V, et al. Curcumin-loaded nanoparticles based on amphiphilic hyaluronan-conjugate explored as targeting delivery system for neurodegenerative disorders. Int J Mol Sci. 2020;21(22):8846. doi:10.3390/ ijms21228846

213. Bhatt R, Singh D, Prakash A, Mishra N. Development, characterization and nasal delivery of rosmarinic acid-loaded solid lipid nanoparticles for the effective management of Huntington's disease. Drug Deliv. 2015;22(7):931-939. doi:10.3109/10717544. 2014.880860

214. Dolati S, Babaloo Z, Jadidi-Niaragh F, Ayromlou H, Sadreddini S, Yousefi M. Multiple sclerosis: therapeutic applications of advancing drug delivery systems. Biomed Pharmacother. 2017;86:343-353. doi:10.1016/j.biopha.2016.12.010

215. Kumar P, Sharma G, Gupta V, et al. Preclinical explorative assessment of dimethyl fumarate-based biocompatible nanolipoidal carriers for the management of multiple sclerosis. ACS Chem Neurosci. 2018;9(5):1152-1158. doi:10.1021/acschemneuro.7b00 519

216. Kumar P, Sharma G, Kumar R, et al. Vitamin-derived nanolipoidal carriers for brain delivery of dimethyl fumarate: a novel approach with preclinical evidence. ACS Chem Neurosci. 2017;8 (6):1390-1396. doi:10.1021/acschemneuro.7b00041

217. Esposito E, Cortesi R, Drechsler M, et al. Nanoformulations for dimethyl fumarate: physicochemical characterization and in vitro/ in vivo behavior. Eur J Pharm Biopharm. 2017;115:285-296. doi:10.1016/j.ejpb.2017.04.011

218. Yang J, Wang L, Huang L, et al. Receptor-targeting Nanomaterials Alleviate Binge Drinking-induced Neurodegeneration as Artificial Neurotrophins. Wiley Online Library; 2021:61-74.

219. Min HS, Kim HJ, Naito M, et al. Systemic brain delivery of antisense oligonucleotides across the blood-brain barrier with a glucose-coated polymeric nanocarrier. Angew Chem. 2020;132 (21):8250-8257. doi:10.1002/ange.201914751

220. Chang X, Li J, Niu S, Xue Y, Tang M. Neurotoxicity of metalcontaining nanoparticles and implications in glial cells. $J$ Appl Toxicol. 2021;41(1):65-81. doi:10.1002/jat.4037
International Journal of Nanomedicine

\section{Publish your work in this journal}

The International Journal of Nanomedicine is an international, peerreviewed journal focusing on the application of nanotechnology in diagnostics, therapeutics, and drug delivery systems throughout the biomedical field. This journal is indexed on PubMed Central, MedLine, CAS, SciSearch ${ }^{\circledR}$, Current Contents ${ }^{\circledR} /$ Clinical Medicine,
Journal Citation Reports/Science Edition, EMBase, Scopus and the Elsevier Bibliographic databases. The manuscript management system is completely online and includes a very quick and fair peer-review system, which is all easy to use. Visit http://www.dovepress.com/ testimonials.php to read real quotes from published authors. 